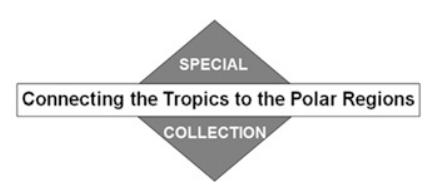

\title{
Comparing the Impacts of Tropical SST Variability and Polar Stratospheric Ozone Loss on the Southern Ocean Westerly Winds*
}

\author{
DAVID P. SCHNEIDER AND ClARA DESER \\ Climate and Global Dynamics Laboratory, $\mathrm{NCAR}^{+}{ }^{+}$Boulder, Colorado \\ TINGTING FAN \\ Climate and Global Dynamics Laboratory, NCAR, Boulder, Colorado, and Key Laboratory of Physical Oceanography, \\ Ocean University of China, Qingdao, China
}

(Manuscript received 30 January 2015, in final form 2 September 2015)

\begin{abstract}
Westerly wind trends at $850 \mathrm{hPa}$ over the Southern Ocean during 1979-2011 exhibit strong regional and seasonal asymmetries. On an annual basis, trends in the Pacific sector $\left(40^{\circ}-60^{\circ} \mathrm{S}, 70^{\circ}-160^{\circ} \mathrm{W}\right)$ are 3 times larger than zonal-mean trends related to the increase in the southern annular mode (SAM). Seasonally, the SAMrelated trend is largest in austral summer, and many studies have linked this trend with stratospheric ozone depletion. In contrast, the Pacific sector trends are largest in austral autumn. It is proposed that these asymmetries can be explained by a combination of tropical teleconnections and polar ozone depletion. Six ensembles of transient atmospheric model experiments, each forced with different combinations of time-dependent radiative forcings and SSTs, support this idea. In summer, the model simulates a positive SAM-like pattern, to which ozone depletion and tropical SSTs (which contain signatures of internal variability and warming from greenhouse gasses) contribute. In autumn, the ensemble-mean response consists of stronger westerlies over the Pacific sector, explained by a Rossby wave originating from the central equatorial Pacific. While these responses resemble observations, attribution is complicated by intrinsic atmospheric variability. In the experiments forced only with tropical SSTs, individual ensemble members exhibit wind trend patterns that mimic the forced response to ozone. When the analysis presented herein is applied to 1960-2000, the primary period of ozone loss, ozone depletion largely explains the model's SAM-like zonal wind trend. The time-varying importance of these different drivers has implications for relating the historical experiments of free-running, coupled models to observations.
\end{abstract}

\section{Introduction}

One of the most discussed aspects of Southern Hemisphere (SH) climate change of the past several decades is the intensification and poleward shift of the midlatitude jet, reflected in stronger westerly winds between $50^{\circ}$ and $70^{\circ} \mathrm{S}$ throughout the depth of the troposphere (e.g., Thompson et al. 2011; Previdi and Polvani 2014). This wind shift projects on the positive phase of

\footnotetext{
* Supplemental information related to this paper is available at the Journals Online website: http://dx.doi.org/10.1175/JCLI-D-15-0090.s1.

${ }^{+}$The National Center for Atmospheric Research is sponsored by the National Science Foundation.
}

Corresponding author address: David P. Schneider, NCAR Climate and Global Dynamics Laboratory, P.O. Box 3000, Boulder, CO 80307-3000.

E-mail: dschneid@ucar.edu the southern annular mode (SAM), which is commonly defined as the leading empirical orthogonal function (EOF) of extratropical, lower-tropospheric geopotential height anomalies (Thompson and Wallace 2000). The positive trend in the SAM has been linked with a reduction in the Southern Ocean carbon sink (e.g., Le Quéré et al. 2007; Lovenduski et al. 2008), shifts in the spatial distribution of precipitation (Kang et al. 2011; Previdi and Polvani 2014), and cooling trends in East Antarctic surface climate (Marshall 2007; Nicolas and Bromwich 2014). There have also been significant regional, nonzonal trends in the atmospheric circulation at middle-to-high latitudes, contributing to Antarctic sea ice anomalies (Holland and Kwok 2012; Li et al.

Publisher's Note: This article was revised on 9 December 2015 to correct the online version of Figure 4, which was mistakenly replaced when originally published. 
2014) and to warming trends on the Antarctic Peninsula (Ding and Steig 2013) and in West Antarctica (Ding et al. 2011; Schneider et al. 2012a).

The most cited cause of the increase in the SAM since the early 1960s is polar stratospheric ozone depletion (e.g., Thompson et al. 2011; Previdi and Polvani 2014). In observations over Antarctica, the austral summer increase in the SAM during 1969-98 broadly parallels the drop in total column ozone concentration (Thompson and Solomon 2002). The response to ozone depletion-a positive trend in the SAM - is consistent across a wide variety of models and experimental designs (e.g., Gillett and Thompson 2003; Son et al. 2010; Polvani et al. 2011; Eyring et al. 2013). Generally, the circulation response to ozone depletion has been attributed to polar stratospheric cooling, which strengthens the meridional temperature gradient between the polar and middle latitudes. This leads to a thermal wind response, but the exact mechanisms of the SAM response remain unclear (e.g., Thompson et al. 2011). The zonal wind response to ozone depletion also resembles the circulation response to tropical heating anomalies associated with global warming or ENSO (e.g., Lu et al. 2008; Sun et al. 2013; Vallis et al. 2014). At least one study has argued that rising SSTs, rather than ozone depletion, were the main cause of zonally symmetric circulation trends in the SH during the twentieth century (Staten et al. 2012). As with the response to ozone depletion, there is no consensus on the most important mechanisms of the response to tropical warming (Vallis et al. 2014). The prevailing argument is that the rising SSTs lead to a meridionally broad, midtropospheric warming in the tropics, which alters the meridional temperature gradient, pushing the latitude of baroclinicity poleward, resulting in a poleward shift of the jet (Vallis et al. 2014).

Apart from Staten et al. (2012), the role of tropical SST forcing in the context of observed SH circulation trends has been interpreted in terms of poleward-propagating Rossby waves, which are associated with zonally asymmetric circulation patterns at middle and high latitudes. These waves, fueled by anomalous deep convection and latent heating in the tropics, are the main pathway of tropicalAntarctic linkages. Several studies, including Ding et al. (2011), Ding and Steig (2013), Li et al. (2014), Simpkins et al. (2014), and Schneider et al. (2012a), have linked recent trends in the zonally asymmetric high-latitude circulation with Rossby waves generated in the tropics.

The recent trends in the tropics reflect, in part, a shift to the negative phase of the Pacific decadal oscillation (PDO) since the late 1990s, characterized by decadalscale cooling of the central and eastern tropical Pacific (e.g., Trenberth et al. 2014) and strengthening of the Pacific trade winds (England et al. 2014). Missing PDO and ENSO teleconnections may be a reason for the underestimation of late-twentieth-century SH zonal wind trends by coupled models participating in phase 5 of the Coupled Model Intercomparison Project (CMIP5) historical experiment (Mahlstein et al. 2013). In these experiments, the models generate their own tropical variability. If this variability does not sync with the phases of the actual PDO and related phenomena like ENSO, these model simulations are unlikely to exhibit the trends in the tropically driven teleconnections that explain a large part of recent Antarctic climate trends (e.g., Ding et al. 2011; Ding and Steig 2013; Schneider et al. 2012a).

Another source of deficiency in CMIP5 simulations may be traceable to the external forcing datasets prescribed. In particular, ozone depletion might be underestimated in some forcing datasets because of sparse source data (Eyring et al. 2013; Hassler et al. 2013) or to limited spatial (Waugh et al. 2009) or temporal resolution (Neely et al. 2014). The sensitivity experiments of Young et al. (2014) suggest that the stronger the ozone depletion prescribed to a given model, the stronger the circulation response.

Over the past several decades, a negative trend in the PDO (reflecting the shift from the positive phase to negative phase in 1998; see Trenberth et al. 2014) coincided with a decline of ozone concentration over Antarctica to historically low values. In this study, we investigate the impacts of these two trends on the $\mathrm{SH}$ atmospheric circulation using multiple ensembles of transient atmospheric model integrations in which observed tropical SSTs (which capture the variability of the PDO) and different combinations of radiative forcings are prescribed. While previous work provides descriptions of the responses to ozone depletion and tropical SSTs separately, few studies have directly compared and quantified these two responses and assessed the extent to which they combine to explain the observed trend patterns. We also highlight the role of intrinsic variability through inclusion of results from individual ensemble members and discuss how it can complicate attribution.

For the response to ozone depletion, the sensitivities to two different forcing datasets are compared; one of these has relatively aggressive ozone loss, while the other has been widely used but criticized for its relatively weak ozone depletion. We group nonozone radiative forcings [including greenhouse gasses (GHGs), natural and anthropogenic aerosols, solar variability, etc.] into a single category of "other" forcing. This is motivated by the fact that the direct impacts of these other radiative forcings (i.e., the components of the response not mediated by SSTs) have been previously found to be very small relative to the effects of ozone 
TABLE 1. Summary of the experiments conducted with CAM4. The nonozone radiative forcings are consistent with those used in the CMIP historical simulations with the CCSM4 (Gent et al. 2011). Further details are given in section 2 of the main text.

\begin{tabular}{|c|c|c|c|}
\hline Expt No. and name & Time-varying forcing & Climatological forcing & Years and No. of runs \\
\hline 1) Ozone (SPARC) & $\mathrm{SPARC} \mathrm{O}_{3}$. & $\begin{array}{l}\text { All SSTs and sea ice and all } \\
\text { non- } \mathrm{O}_{3} \text { radiative forcings. }\end{array}$ & 1950-2011, 5 runs \\
\hline 2) Ozone (WACCM) & $\mathrm{WACCM} \mathrm{O}_{3}$. & $\begin{array}{l}\text { All SSTs and sea ice and all } \\
\text { non- } \mathrm{O}_{3} \text { radiative forcings. }\end{array}$ & 1950-2011, 5 runs \\
\hline 3) Tropical SST & Tropical SSTs $\left(28^{\circ} \mathrm{N}-28^{\circ} \mathrm{S}\right)$. & $\begin{array}{l}\text { Extratropical SSTs and sea ice } \\
\text { and all radiative forcings. }\end{array}$ & 1900-2011, 5 runs \\
\hline 4) Partial Forcing & $\begin{array}{l}\text { Tropical SSTs }\left(28^{\circ} \mathrm{N}-28^{\circ} \mathrm{S}\right) \text { and all radiative } \\
\text { forcings except } \mathrm{O}_{3} \text {. }\end{array}$ & $\begin{array}{l}\text { Extratropical SSTs and sea } \\
\text { ice and } \mathrm{O}_{3} \text {. }\end{array}$ & 1950-2011, 5 runs \\
\hline 5) Full Forcing (SPARC) & $\begin{array}{l}\text { Tropical SSTs }\left(28^{\circ} \mathrm{N}-28^{\circ} \mathrm{S}\right) \text { and all radiative } \\
\text { forcings using SPARC O } \mathrm{O}_{3} \text {. }\end{array}$ & Extratropical SSTs and sea ice. & 1950-2011, 5 runs \\
\hline 6) Full Forcing (WACCM) & $\begin{array}{l}\text { Tropical SSTs }\left(28^{\circ} \mathrm{N}-28^{\circ} \mathrm{S}\right) \text { and all radiative } \\
\text { forcings using WACCM O } \mathrm{O}_{3} \text {. }\end{array}$ & Extratropical SSTs and sea ice. & 1950-2011, 5 runs \\
\hline
\end{tabular}

and SSTs (e.g., Deser and Phillips 2009; Polvani et al. 2011; Staten et al. 2012; Grise and Polvani 2014). Our experiments do not address the extent to which the tropical SSTs themselves have changed in response to external forcing or, conversely, how tropically generated variability might have influenced stratospheric ozone concentrations.

Although the bulk of our analysis is focused on the period 1979-2011, our experiments are conducted over a longer time period with a view toward future work as well as an examination of sensitivity to the time period of analysis. Different time periods are characterized by different superpositions of tropical variability and ozone loss than is 1979-2011, with implications for the relative roles of different forcings.

\section{Experiments, data, and methods}

\section{a. Model and experiments}

This study uses the Community Atmosphere Model, version $4(\mathrm{CAM} 4)$, configured at a $0.9^{\circ}$ latitude $\times 1.25^{\circ}$ longitude horizontal resolution with finite volume dynamical core and 26 vertical levels (Neale et al. 2013). CAM4 simulates realistic SH circulation responses to tropical variability (Wilson et al. 2014). Its predecessor, CAM3, has been widely used to study the response to stratospheric ozone depletion (Polvani et al. 2011; Young et al. 2014).

Six ensembles of transient experiments are conducted with CAM4, as outlined in Table 1. The first two ensembles consist of ozone sensitivity experiments, forced by time-varying ozone concentrations from two different ozone datasets described below. In these experiments, SSTs, sea ice concentrations, and nonozone radiative forcings are held to seasonally varying climatologies. We refer to these first two experiments together as the Ozone ensemble. The remaining four ensembles use common
SST and sea ice concentration lower boundary conditions: Observed time-varying tropical SSTs are prescribed over $28^{\circ} \mathrm{N}-28^{\circ} \mathrm{S}$, and a seasonally varying climatology for SSTs and sea ice concentrations is used poleward of $35^{\circ}$. Between $28^{\circ}$ and $35^{\circ}$ latitude in both hemispheres, the SST anomalies are tapered by adding damped anomalies (linearly weighted by latitude) to the climatologies. The Tropical SST (TSST) experiment is forced by time-varying tropical SSTs only; the radiative forcings have no time dependence beyond the seasonal cycle. The Partial Forcing experiment is forced by time-varying tropical SSTs plus all radiative forcings except ozone. The final experiments, referred to as the Full Forcing experiments, are forced by time-varying tropical SSTs and the full suite of radiative forcings, including ozone. In all experiments, the external forcings without time dependence beyond the seasonal cycle are set to climatological values for the year 2000; the SST and sea ice concentration climatologies are based on the period 1900-2010. All experiments have five ensemble members, initialized from different atmospheric states taken from a control simulation of the coupled version of CAM4, the Community Climate System Model, version 4 (CCSM4; Gent et al. 2011).

\section{b. Boundary conditions, reanalysis, and observations}

The SST and sea ice concentration boundary conditions are from the dataset of Hurrell et al. (2008). For the nonozone external forcings, the datasets are the same as those used for the CMIP5 twentieth-century historical experiments with CCSM4 (Gent et al. 2011). The external forcings are extended beyond the year 2005 with values from the representative concentration pathway 8.5 (van Vuuren et al. 2011).

The first ozone dataset, referred to as the StratosphereTroposphere Processes and Their Role in Climate (SPARC) dataset, was developed for and widely used by numerous models for their CMIP5 historical experiments (Cionni et al. 2011; Eyring et al. 
a) SON SPARC Ozone <50hPA, 65S-90S>

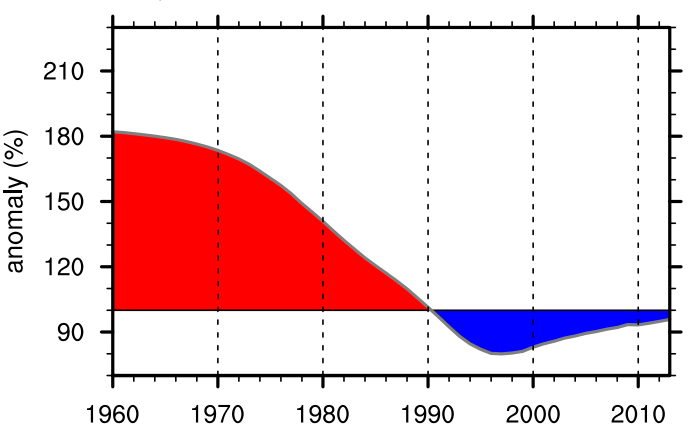

c) DJF SPARC Ozone <50hPA, 65S-90S $>$

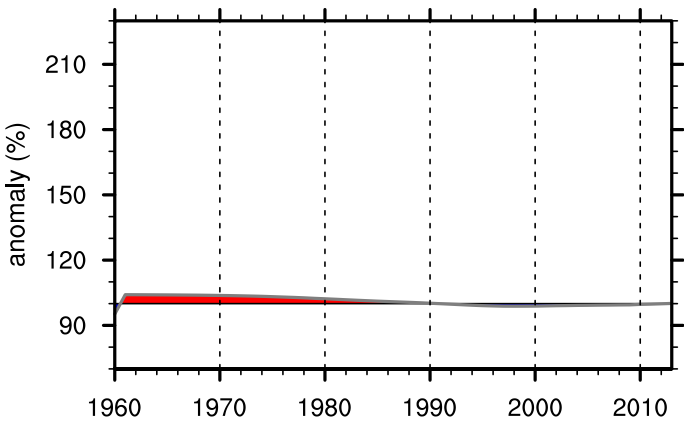

b) SON WACCM Ozone <50hPA, 65S-90S>

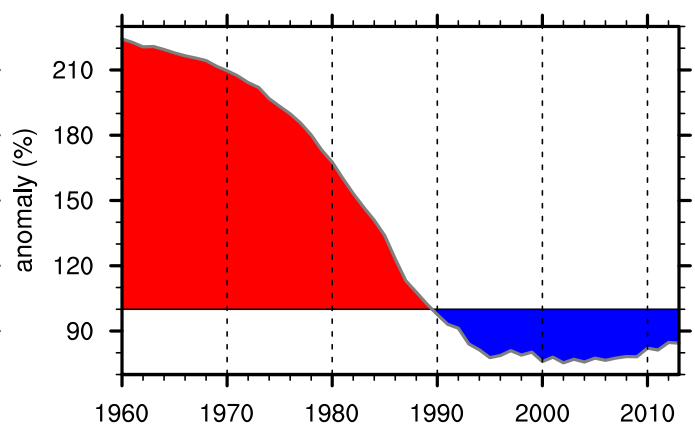

d) DJF WACCM Ozone <50hPA, 65S-90S >

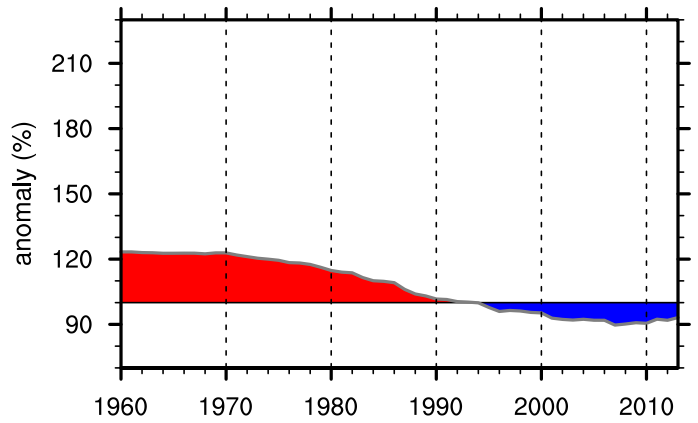

FIG. 1. Seasonal-mean time series of relative ozone concentration over $65^{\circ}-90^{\circ} \mathrm{S}$ at $50 \mathrm{hPa}$ in the SPARC and WACCM forcing datasets for (a) SON SPARC, (b) SON WACCM, (c) DJF SPARC, and (d) DJF WACCM. The values are percentages relative to the 1979-2011 long-term mean, calculated for each record separately.

2013). The SPARC data are monthly mean, zonal-mean, vertically resolved ozone fields. For the primary period of interest here (1979-2011), the SPARC stratospheric ozone data are based on regression fits (representing different time scales and processes of variability) to ozonesonde observations. However, these observations are sparse: SPARC included observations from only one location in the $\mathrm{SH}$ polar region, Syowa station $\left(69.0^{\circ} \mathrm{S}\right.$, $\left.39.6^{\circ} \mathrm{E}\right)$. As Syowa is located near the edge of the polar vortex, it does not experience the severe ozone depletion that can occur in the deep interior of the polar vortex (Eyring et al. 2013). Comparing the SPARC austral spring polar stratospheric ozone values $\left(65^{\circ}-\right.$ $90^{\circ} \mathrm{S} ; 100-10 \mathrm{hPa}$ ) with a more complete set of in situ ozonesonde measurements, Hassler et al. (2013) find that SPARC values lie within but toward the high end of the observed range.

The second ozone dataset consists of monthly averaged ozone concentrations calculated interactively by the Whole Atmosphere Community Climate Model (WACCM), a high-top chemistry-climate model (Marsh et al. 2013). This dataset, referred to here as the WACCM ozone dataset, is independent of the SPARC dataset, as it is based on a model experiment with specified emissions of ozone-depleting substances (Marsh et al.
2013), rather than on direct ozonesonde observations. Unlike the zonal-mean SPARC data, the WACCM data vary with latitude and longitude. In austral spring, WACCM-estimated ozone concentrations agree very well with Antarctic ozonesonde observations over the 1979-2005 period, while in summer, WACCM's ozone depletion is too severe, likely due to the model's seasonal polar vortex persisting too long (Marsh et al. 2013). Kay et al. (2015) describe the transformation of the WACCM-simulated ozone into a prescribed forcing dataset. Externally forced ozone variations are emphasized over the model-generated internal variability by applying a $10-y r$ running mean to the WACCM ozone concentrations, using separate time series for each month.

Figure 1 compares WACCM and SPARC time series of relative ozone concentration over $65^{\circ}-90^{\circ} \mathrm{S}$ at $50 \mathrm{hPa}$ in austral spring [September-November (SON)] and summer [December-February (DJF)]. Both datasets are temporally smooth and exhibit a broadly similar progression of ozone loss in SON, with the maximum values occurring at the beginning of the period and the minimum values occurring in the mid-1990s. WACCM ozone loss is more rapid than SPARC ozone loss. For example, during the 1980s, WACCM ozone declines by 
about $70 \%$ of its long-term mean value, but SPARC ozone declines by only about $40 \%$ of its long-term mean value. From the mid-1990s onward, SPARC ozone recovers somewhat, but WACCM values remain very low. In DJF, the difference between the WACCM and SPARC time series is more striking than in SON: WACCM exhibits strong ozone loss while SPARC has almost no trend.

Trends in zonal wind and air temperature are computed from monthly fields of the ERA- Interim (ERAI; Dee et al. 2011). To place the reanalysis winds trends in the context of other climate variables and observational data, the winds are compared with SSTs from the Hurrell et al. (2008) dataset mentioned above, and rainfall data from the Global Precipitation Climatology Project, version 2.2 (Adler et al. 2003). The ERAI data are chosen because, among the major reanalyses, ERAI is superior in terms of its depiction of the major circulation features at high $\mathrm{SH}$ latitudes and shows trends consistent with those in station-based, largescale climate indices (Bracegirdle and Marshall 2012; Bracegirdle 2013). For temperature, the main region of interest here is the polar lower stratosphere. The ERAI temperature anomalies at $100 \mathrm{hPa}$ over $65^{\circ}-90^{\circ} \mathrm{S}$ show excellent agreement in terms of interannual variability and trends during their period of overlap with the station-average upper-air temperature time series compiled by Screen and Simmonds (2012) (see Fig. S1 in the supplemental material). As the Screen and Simmonds (2012) data have coarse temporal resolution and limited spatial coverage, they are not directly used in this this study.

\section{c. Methods}

The sensitivity experiments described above enable two methods to infer the role of ozone forcing. First, the forced response to ozone can be obtained directly from the ensemble means of the first two sets of experiments in Table 1. A second approach is to difference the ensemble means of the Full Forcing and Partial Forcing integrations. Both approaches are applied for the SPARC- and WACCM-forced ensembles separately and in combination. The austral summer, 1960-2000 zonal-mean zonal wind and temperature trends for these two methods and two ozone datasets are compared in Fig. S2 of the supplemental material. In general, there are more noticeable differences associated with the choice of dataset than with the method. The approximate linearity of responses to external forcing, also found in previous studies (e.g., Deser and Phillips 2009), supports use of the differencing method to infer the direct impacts of nonozone radiative forcings (herein referred to as Other Forcing). The response to Other
Forcing is obtained by differencing the ensemble means of the Partial Forcing and TSST integrations.

For a robust estimate of the forced response to ozone that leverages the strengths and weaknesses to the two datasets, we use the mean of the responses to SPARC and WACCM ozone: that is, the ensemble mean of all 10 single-forcing integrations (5 runs using WACCM ozone and 5 runs using SPARC ozone). Similarly, we will discuss the Full Forcing response as the ensemble mean of all 10 of the Full Forcing integrations. However, we will also highlight the aspects in which the responses to SPARC and WACCM ozone forcing are distinct, based on comparisons of the 5-member ensembles.

Linear least squares analysis is used to compute trends and regression coefficients. Throughout this paper, the calculation of statistical significance is based on the twosided Student's $t$ test methodology and adjustment for autocorrelation outlined by Santer et al. (2000). Both the sample size and the degrees of freedom for indexing the critical $t$ value are adjusted according to the lag-1 autocorrelation of the residuals. Note that this significance test is based only on the trend and variance of the observations or the ensemble mean of the model simulations. Another metric for determining if a forced trend may be considered detectable is the signal-to-noise ratio (SNR), where the signal is the ensemble-mean trend and the noise is the standard deviation of the trends across ensemble members. This second approach better accounts for the internal variability as estimated by the model than does the ensemble-mean time series approach; however, it is typically more applicable for large ensemble sizes where the SNR is better constrained (e.g., Deser et al. 2014). For the results emphasized here-namely, the austral summer response of the circumpolar zonal winds to tropical SSTs and ozone depletion and the austral autumn response of the zonal winds in the South Pacific basin to tropical SSTs-we estimate the SNRs in addition to applying the $t$ test.

Seasons in this paper refer to the austral seasons (e.g., summer is DJF). Nonconventional 3-month seasonal means are also used, referred to by the first letters of the corresponding month names [e.g., January-March is JFM].

\section{Results}

\section{a. Zonal wind trends in the reanalysis}

The pattern of $850-\mathrm{hPa}$ zonal wind trends during 1979-2011 using all months (Fig. 2a) suggests that the largest westerly (positive) wind trends on Earth have occurred over the Southern Ocean, particularly in the Pacific sector (outlined by the black box in Fig. 2a). 
a) U850 trend
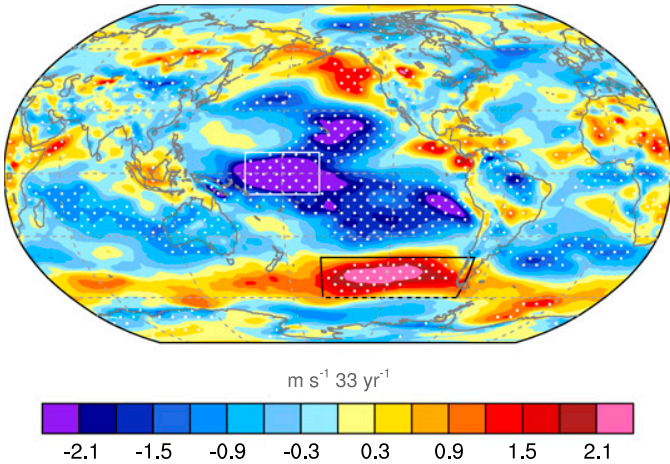

c) EOF1 of U850, <30S-70S>

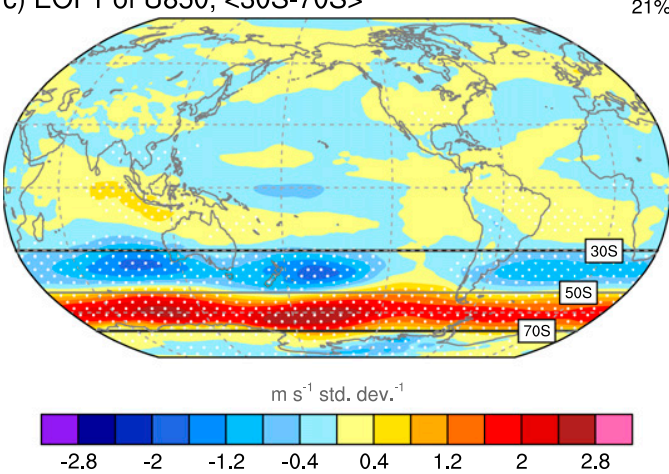

e) U850 trend congruent with EOF1+EOF2

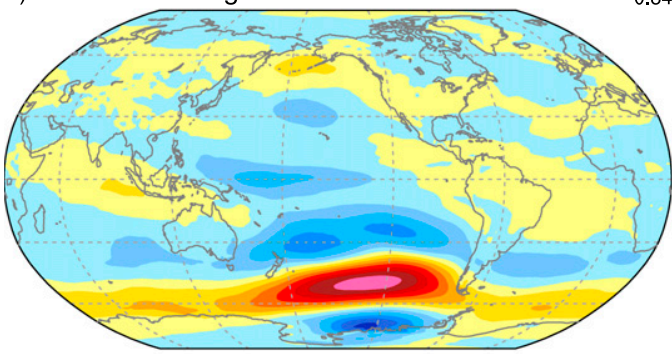

$\mathrm{m} \mathrm{s}^{-1} 33 \mathrm{yr}^{-1}$

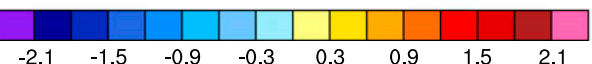

b) SST and tropical rainfall trend

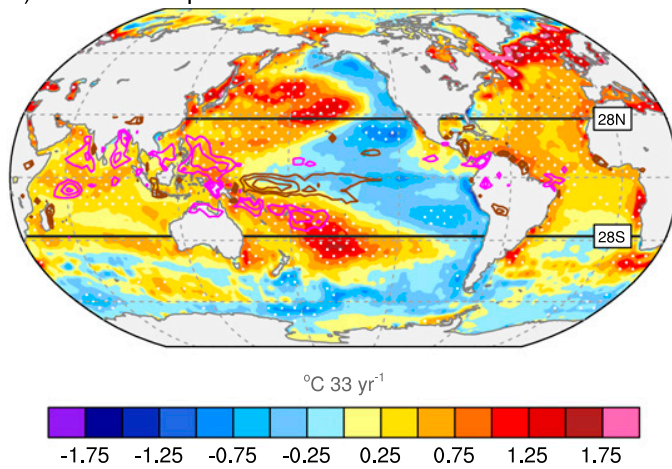

d) EOF2 of U850, <30S-70S> $13 \%$

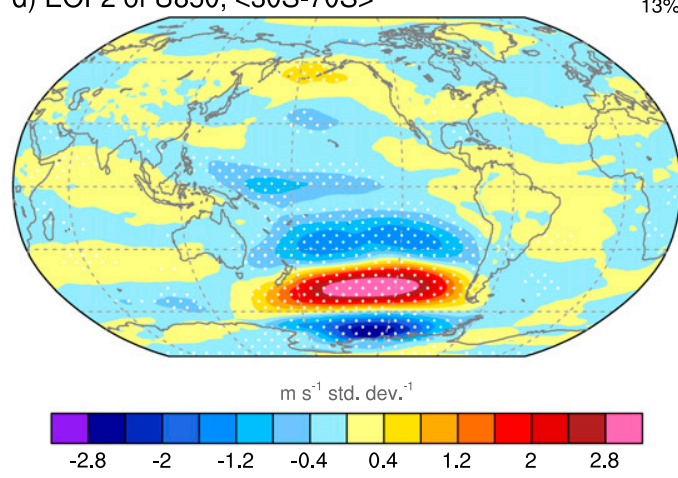

f) SST trend with zonal-mean trend removed

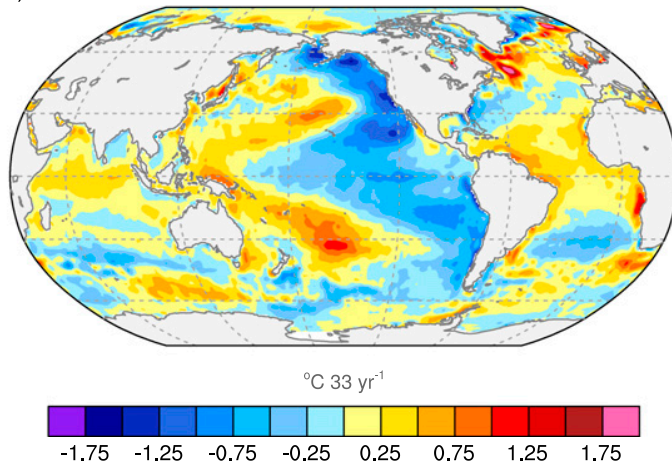

FIG. 2. Trends over 1979-2011, using all months, for (a) 850-hPa zonal wind and (b) SST and tropical rainfall. The SST trends correspond with the color shading. Negative rainfall trends are in brown contours, and positive rainfall trends are in magenta [contoured at $\pm 1.0, \pm 1.5$, and $\pm 2.0 \mathrm{~mm} \mathrm{day}^{-1}(33 \mathrm{yr})^{-1}$. The (c) first and (d) second EOF patterns of the monthly 850 -hPa zonal wind anomalies over $30^{\circ}-70^{\circ} \mathrm{S}$, the region bounded by the lines in (c). The patterns were obtained by regressing the global zonal wind anomalies onto the standardized PC time series. For all panels, white stippling indicates that the trend or regression coefficient is significant at or above the $95 \%$ level. The white and black boxes in (a) correspond with the areas used to represent winds in the equatorial Pacific and in the Pacific sector of the Southern Ocean, respectively. The latitudes bounding the time-varying tropical SST forcing of the model integrations are indicated in (b). (e) The trend in $850-\mathrm{hPa}$ zonal wind that is congruent with the first two EOFs; (f) the global SST trends with the zonal-mean trend removed at each latitude.

Westerly trends extend across the Southern Ocean at approximately $60^{\circ} \mathrm{S}$, though they are not statistically significant at all longitudes. Easterly (negative) wind trends cover most of the Pacific basin between $30^{\circ} \mathrm{N}$ and $30^{\circ} \mathrm{S}$, with the largest values occurring in the central and western equatorial Pacific (white box in Fig. 2a).
Negative SST trends (Fig. 2b) over much of the Southern Ocean accompany the westerly wind trends. The negative SST trends are consistent with oceanic responses to stronger westerlies via anomalies in mixed layer depth, Ekman transport, and air-sea heat fluxes (e.g., Sallée et al. 2010). In the Pacific basin of both 
hemispheres, the pattern of negative SST trends in the east and positive SST trends in the west resembles the negative phase of the PDO (England et al. 2014; Trenberth et al. 2014). The east-west contrast in SST trends is consistent with stronger trade winds and faster subtropical oceanic gyres (England et al. 2014). The negative rainfall trends over the central tropical $\mathrm{Pa}-$ cific (Fig. 2b) imply strongly negative diabatic heating anomalies, giving rise to the expectation of an atmospheric Rossby wave response that may impact the SH atmospheric circulation (Trenberth et al. 2014). With the zonal-mean trend removed, the central and eastern Pacific cooling stands out as anomalous (Fig. 2f), which sets the stage for the circulation response in the model simulations described below.

To relate the observed wind trend pattern to the two leading modes of $\mathrm{SH}$ atmospheric circulation variability, an EOF analysis of the monthly zonal wind anomalies over $30^{\circ}-70^{\circ} \mathrm{S}$ is performed. The first EOF (Fig. 2c) explains $21 \%$ of the variance and is associated with anomalies of one sign between $30^{\circ}$ and $50^{\circ} \mathrm{S}$ and of the opposite sign between $50^{\circ}$ and $70^{\circ} \mathrm{S}$. Wind anomalies associated with the second EOF (Fig. 2d), which explains $13 \%$ of the variance, are largely confined to the Pacific and are consistent with a wave train extending from the tropics to the Antarctic. The zonal wind anomalies related to the second EOF reflect a cyclonic circulation feature centered near $60^{\circ} \mathrm{S}, 120^{\circ} \mathrm{W}$. This is the approximate average position of the Amundsen Sea low, a semipermanent low pressure center that has deepened in recent decades (Raphael et al. 2015), consistent with the zonal wind trends in the Pacific sector.

The principal component (PC) time series of the two leading modes of zonal wind variability (Figs. 3a,b) both exhibit positive trends, but the trend in $\mathrm{PC} 2$ is larger than the trend in $\mathrm{PC} 1$, signaling the relatively larger trends in the Pacific sector of the Southern Ocean. PC1 exhibits relatively high-frequency variability and is highly correlated ( $r=0.88$; significant at $99 \%)$ with the SLP-based SAM index of Marshall (2003), which is displayed in Fig. 3c. Anomalies in PC2 exhibit greater persistence than anomalies in PC1, consistent with the idea that much of the variance in $\mathrm{PC} 2$ arises from tropical variability (both PDO and ENSO). Indeed, there is a correlation of $r=0.55$ (significant at 95\%) between PC2 and the time series of zonal wind from the central equatorial Pacific (Fig. 3d), which in turn is correlated with the PDO index at $r=0.45$ (significant at $95 \%$ ). Although PC2 has more high-frequency noise than the equatorial Pacific index because of its extratropical emphasis, both time series show multiyear periods of positive anomalies, especially after the late 1990s when the PDO transitioned to its negative phase.
The EOF analysis reveals that the spatial pattern of the wind trend indeed projects onto the leading modes of variability. The zonal band of positive values between $50^{\circ}$ and $70^{\circ} \mathrm{S}$ projects onto the first mode, and the broader latitudinal extent of stronger positive values in the Pacific sector projects onto the second mode. The trend pattern linearly congruent with the sum of the two modes, obtained by multiplying the leading two regression patterns (based on detrended data) by the trend of their respective PCs and summing the two patterns (Fig. 2e) has a correlation of $r=0.84$ with the observed trend pattern (Fig. $2 \mathrm{a}$ ) over $30^{\circ}-70^{\circ} \mathrm{S}$. The distinct time series corresponding to these leading modes suggests that two processes may be at play to explain the observed zonal wind trend, the first largely focused on the zonal-mean circulation at high latitudes, and the second focused regionally on the Pacific sector, with a significant connection to the tropics.

For comparison with the model integrations, we construct two indices of the monthly zonal wind field, guided by the observed EOF and trend patterns. The first index, correlated at $r=0.96$ with PC1, is the areal average of the wind field over $50^{\circ}-70^{\circ} \mathrm{S}$ across all longitudes; this index is analogous to the SAM index, and we will refer to its spatial signature as the SAM-like pattern. Second, a Pacific sector index, correlated at $r=$ 0.87 with $\mathrm{PC} 2$, is calculated as the areal average over the region outlined in Fig. $2 \mathrm{a}\left(40^{\circ}-60^{\circ} \mathrm{S}, 70^{\circ}-160^{\circ} \mathrm{W}\right)$. Unlike the PCs, these indices are not necessarily orthogonal, and there is a small overlap in their domain. Nonetheless, these indices (Figs. 3e,f) exhibit temporal characteristics similar to their PC counterparts (Figs. 3a,b), with sufficient distinction to relate them to different driving processes.

Another defining characteristic of the zonal wind trend is its seasonality. Trends in the SAM-like pattern are highly seasonally dependent (Fig. 4), with the largest positive trend occurring in DJF and near-zero or negative trends occurring in JJA through SON. Trends in the Pacific sector are less seasonally dependent, with positive trends year-round, peaking and most significant in autumn. Annually, the Pacific sector trend is 3 times larger than the trend related to the SAM. The spatial and seasonal asymmetries of the zonal wind trends are the key aspects that we highlight as we relate the observed trends, as estimated by the reanalysis, to the model experiments.

\section{b. Modeled zonal wind trends: Spatial patterns and their seasonality}

Figure 5 depicts the simulated ensemble-mean trends during 1979-2011. In response to Full Forcing, significant westerly trends extend across the Southern Ocean, 


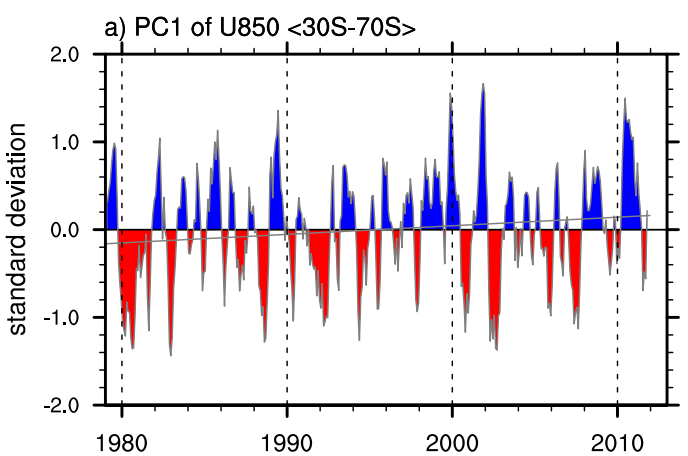

b) PC2 of U850 <30S-70S $>$
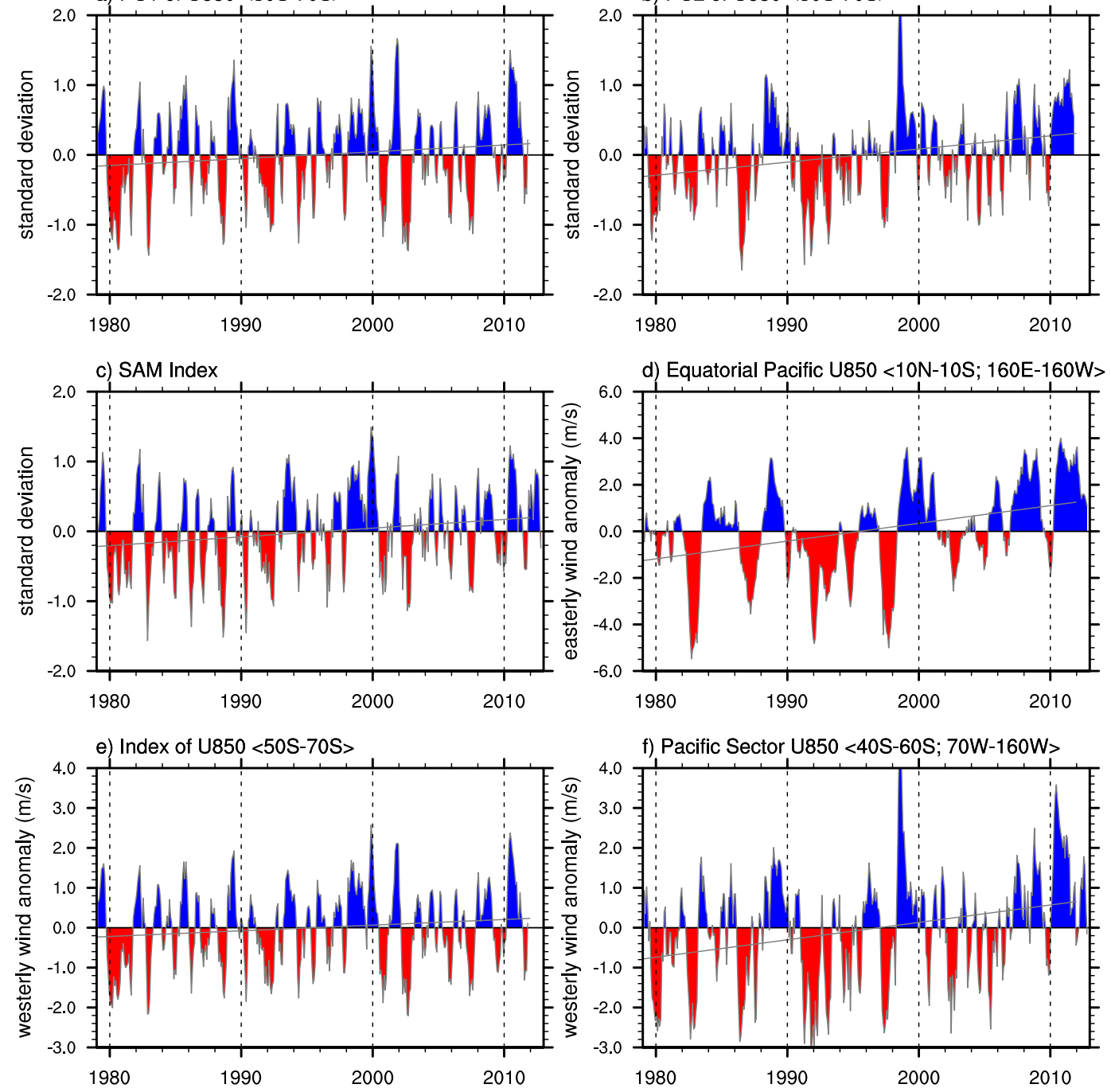

FIG. 3. Monthly mean time series of (a) PC1 of 850-hPa zonal wind corresponding to the pattern in Fig. 2c; (b) PC2 of 850-hPa zonal wind corresponding to the pattern in Fig. 2d; (c) the SAM index of Marshall (2003); (d) equatorial Pacific wind anomalies averaged over the white box in Fig. $2 \mathrm{a}$; (e) indices of zonal wind anomalies over $50^{\circ}-70^{\circ} \mathrm{S}$; and (f) the Pacific sector. All time series are smoothed with a 4-month running mean.

and easterly trends cover the central and western tropical Pacific (Fig. 5a). In the SH, the largest westerly trends occur in the Pacific sector. This pattern is broadly similar to the trends in ERAI (pattern correlation over $30^{\circ}-70^{\circ} \mathrm{S}$ is 0.72 and globally 0.62 ).

The trend pattern in the TSST ensemble (Fig. 5b) resembles that of the Full Forcing ensemble, showing again westerly trends across the Southern Ocean with stronger trends in the Pacific sector. However, these trends are somewhat weaker than the trends in the Full Forcing ensemble. This difference is explained mainly by the ozone response (Fig. 5c), characterized by westerly trends between $50^{\circ}$ and $70^{\circ} \mathrm{S}$ and easterly trends between $30^{\circ}$ and $50^{\circ} \mathrm{S}$, resembling the SAM pattern in
Fig. 2c. The sum of the TSST and Ozone ensemble trends (Fig. 5e) exhibits a strong pattern correlation $(r=$ 0.80 ) over $30^{\circ}-70^{\circ} \mathrm{S}$ with the reanalysis trend and closely resembles the Full Forcing trend. This illustrates the approximate linearity of the responses to tropical SSTs and ozone and suggests a minor role for Other Forcing. Therefore, the remainder of this analysis focuses on the responses to tropical SSTs and ozone.

Figures 6 and 7 characterize the modeled circulation patterns in terms of the two zonal wind indices and stratify their trends by season. Trends in the SAM-like pattern (Fig. 6) exhibit marked seasonality in the Full Forcing ensemble mean (Fig. 6a), both in terms of magnitude and statistical significance. The largest 


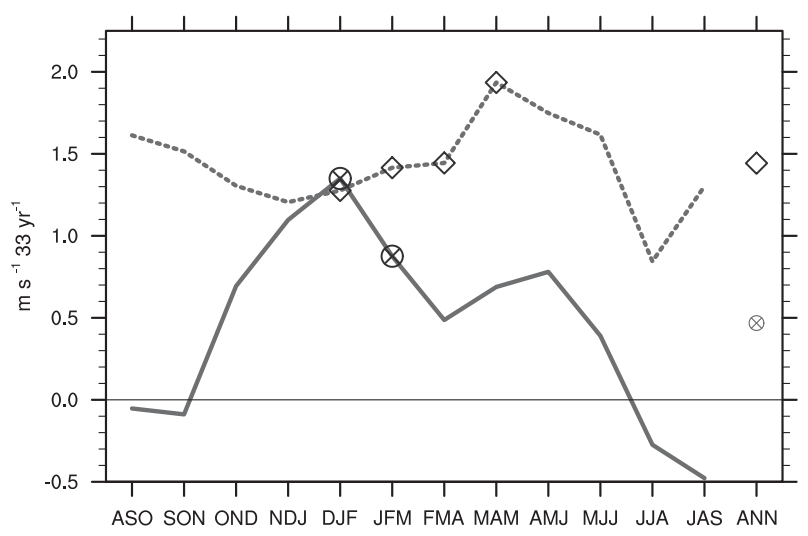

FIG. 4. Seasonal-mean 850-hPa zonal wind trends (from ERAI) during $1979-2011$ for $50^{\circ}-70^{\circ} \mathrm{S}$ (solid line) and the Pacific sector (dashed line). Markers on the seasonal lines indicate statistical significance at or above $90 \%$. Annual (ANN) trends are indicated on the right side. The annual trend for $50^{\circ}-70^{\circ} \mathrm{S}$ is not statistically significant.

trends, significant at the $p<0.01$ level, occur in the late spring through early autumn, peaking in NovemberJanuary (NDJ) and DJF. The minimum trends occur in winter and early spring, similar to the reanalysis. The ensemble spread is also indicated in Fig. 6 a by the thin lines; the trends in ERAI (Fig. 6a, repeated from Fig. 4) lie within the range of individual ensemble members during all seasons, and all members have positive trends from October-December (OND) thru DJF.

The ensemble-mean TSST trends (Fig. 6b) show less seasonal dependence than the Full Forcing trends, with slightly larger trends from spring through late summer than in autumn and winter. A more distinct seasonality is evident in the Ozone ensemble mean (Fig. 6c), which has positive trends from late spring through late summer and near-zero trends in autumn and winter. The ensemble-mean trend is significant (at $p<0.05$ ) in DJF. The amplitude and seasonality of the SAM-like response to Full Forcing is largely explained by the combination of Ozone and TSST experiments. The DJF trend in the SAM-like pattern in the Full Forcing ensemble mean is $1.14 \mathrm{~m} \mathrm{~s}^{-1}(33 \mathrm{yr})^{-1}$, compared to $0.56 \mathrm{~m} \mathrm{~s}^{-1}(33 \mathrm{yr})^{-1}$ for TSST and $0.43 \mathrm{~m} \mathrm{~s}^{-1}(33 \mathrm{yr})^{-1}$ for Ozone. The SNR in DJF for the Full Forcing ensemble is 2.5 , while it is 1.6 for the TSST ensemble and less than one for the Ozone ensemble.

For the Pacific sector index (Fig. 7), trends in both the Full Forcing ensemble (Fig. 7a) and the TSST ensemble (Fig. $7 \mathrm{~b}$ ) are consistently positive year-round in the individual ensemble members. The Full Forcing ensemble-mean trend is most significant (at $p<0.01$ ) in autumn. The TSST ensemble-mean trend is also significant in autumn. In contrast, the Ozone ensemble-mean trends are close to zero for most of the year, but both the SPARC and WACCM ensembles are slightly positive in winter. The comparison of ensemble-mean trends in Fig. 7b illustrates that tropical SSTs largely account for the trend in the Full Forcing ensemble mean in autumn, from February-April (FMA) through April-June (AMJ). In March-May (MAM), the SNR is larger for the TSST ensemble mean (2.0) than it is for the Full Forcing ensemble mean (1.4), underscoring the important role of tropical SSTs in the wind trends in the Pacific sector. In winter and spring, external forcings enhance the trend in the Pacific sector, although the ensemble spread is largest in these seasons.

The maps in Fig. 8 provide a complimentary view of the seasonal zonal wind responses to Full Forcing, Tropical SST, and Ozone experiments. In summer (DJF), both tropical SST and ozone contribute to the trend pattern of the Full Forcing ensemble mean, which in turn is statistically significant and well correlated with the observed trend pattern (pattern correlation over $30^{\circ}-$ $70^{\circ} \mathrm{S}$ is 0.74 ). The pattern correlations in DJF are lower considering TSST or Ozone experiments separately. In autumn (MAM), only tropical SST makes a significant contribution to the trend pattern of the Full Forcing ensemble mean, and this trend is concentrated in the Pacific sector, as it is in the reanalysis, giving a pattern correlation over $30^{\circ}-70^{\circ} \mathrm{S}$ of 0.76 . In the winter and spring, the forced responses associated with TSST and Full Forcing show roughly similar patterns to MAM, but there are not high pattern correlations with the trends in ERAI. Reasons for the less significant responses in JJA and $\mathrm{SON}$ are discussed in section $3 \mathrm{~d}$ below.

\section{c. Summer (DJF) zonal wind response and the roles of tropical SSTs and ozone}

Following from the result that tropical SST and ozone depletion contribute jointly to the Full Forcing zonal wind response in DJF and that the trend pattern at $850 \mathrm{hPa}$ is roughly zonally symmetric (Fig. $8 \mathrm{~b}$ ), the zonal-mean zonal wind and temperature trends associated with these forcings are displayed in Fig. 9 as a function of height and latitude. In ERAI (Fig. 9a), westerly wind trends are centered at about $60^{\circ} \mathrm{S}$ and extend throughout the depth of the troposphere and lower stratosphere, mainly on the poleward side of the climatological jet. The wind trends are accompanied by stratospheric cooling, strongest at approximately $100 \mathrm{hPa}$ over the pole, and by tropospheric warming in the tropics and midlatitudes (Fig. 9b). The patterns of wind and temperature trends in the Full Forcing ensemble mean (Figs. 9c,d) are similar to the reanalysis. Both tropical SSTs (Fig. 9e) and ozone depletion (Fig. 9g) are associated with westerly trends centered at 
a) Full Forcing

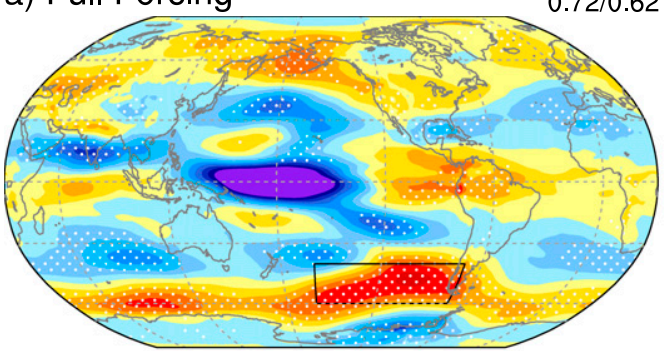

c) Ozone

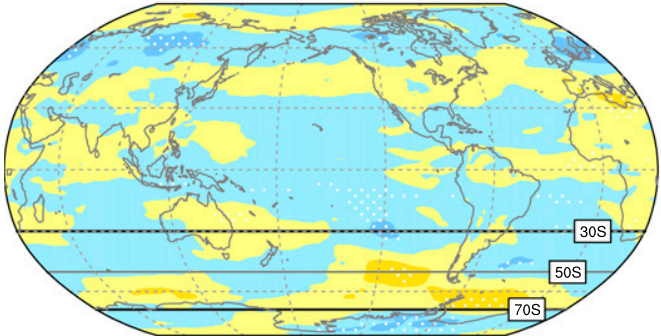

e) Tropical SST + Ozone
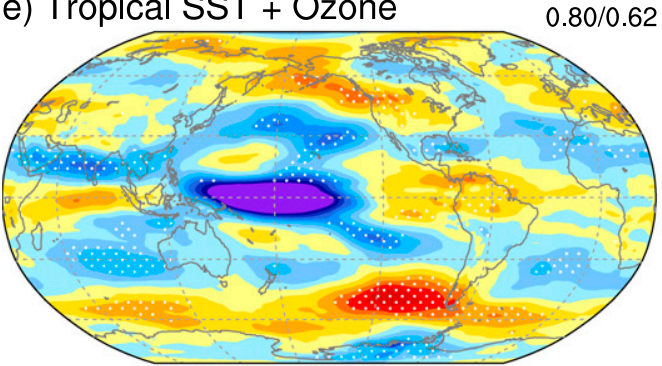

b) Tropical SST

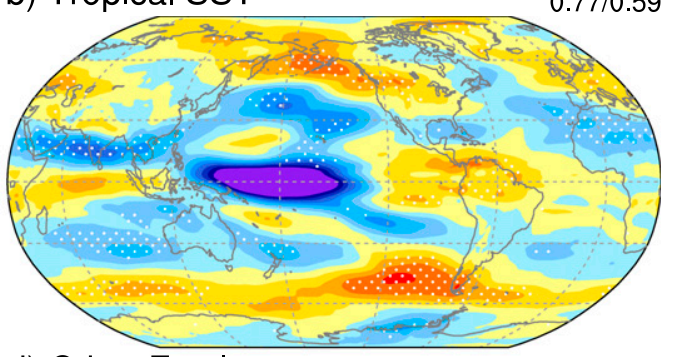

d) Other Forcing

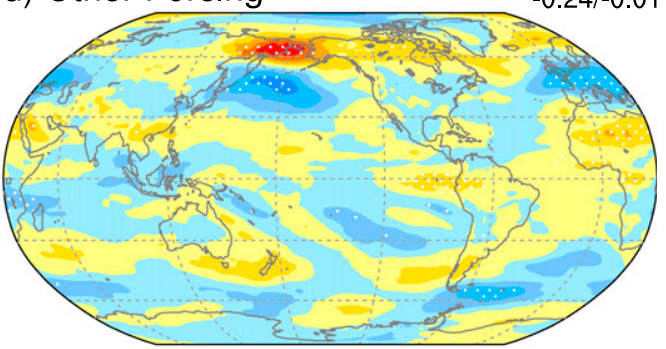

f) ERAI

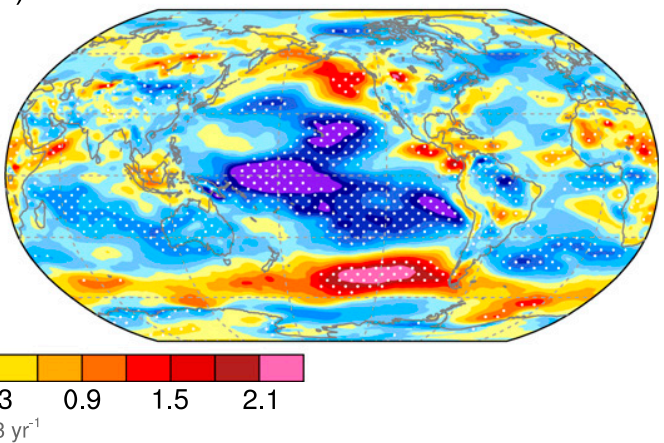

FIG. 5. Maps of simulated ensemble-mean trends in 850-hPa zonal wind over 1979-2011, using all months, for the (a) Full Forcing, (b) TSST, (c) Ozone, (d) Other Forcing, and (e) sum of Tropical SST and Ozone ensembles. For all panels, white stippling indicates that the trend is significant at or above the $95 \%$ level. The numbers at the top right of each map in (a)-(e) are the pattern correlations with (f) the ERAI trend pattern over $30^{\circ}-70^{\circ} \mathrm{S}$ and globally.

$60^{\circ} \mathrm{S}$ that extend throughout the troposphere. Although the ozone-induced wind trends are generally larger than the trends associated with tropical SSTs, they do not account for the entire magnitude of the trends in the Full Forcing ensemble mean. In the lower troposphere, note that the ozone-induced trends, while equal to or stronger than the trends associated with tropical SSTs, occupy a relatively narrow meridional extent. The broader extent of the TSST-induced trends helps to explain their relatively large magnitude when calculated at $850 \mathrm{hPa}$ over $50^{\circ}-70^{\circ} \mathrm{S}$, as discussed above.

The individual roles of tropical SSTs and ozone are evident in the zonal-mean temperature trends (Figs. $9 \mathrm{~d}, \mathrm{f}, \mathrm{h})$. The main thermal signature of ozone depletion resides in the polar lower stratosphere, where significant cooling occurs (Fig. 9h). Tropospheric warming in the tropics and midlatitudes, evident in the reanalysis (Fig. 9b) and Full Forcing ensemble mean (Fig. 9d), can only be explained by tropical SSTs (Fig. 9f), not by ozone (Fig. 9h). As discussed in the introduction, an intensification of the westerlies at high latitudes in response to tropical warming has been found by a number of studies (e.g., Kushner et al. 2001; Lu et al. 2008; Sun et al. 2013; Staten et al. 2012).

Cooling of the lower polar stratosphere associated with ozone depletion is most pronounced in spring (e.g., Thompson et al. 2011). To confirm that this expected seasonal signature of ozone loss occurs in these experiments, Fig. 10 illustrates the seasonal polar stratospheric $\left(65^{\circ}-90^{\circ} \mathrm{S} ; 100 \mathrm{hPa}\right)$ temperature trends in association with the different forcings. ERAI (gray line, Fig. 10a) shows year-round cooling, significant at better than $p<$ 0.05 from late spring through early winter. The maximum cooling of about $6^{\circ} \mathrm{C}$ occurs in OND and NDJ. Trends in the Full Forcing ensemble are in excellent agreement, showing the same seasonal pattern in 

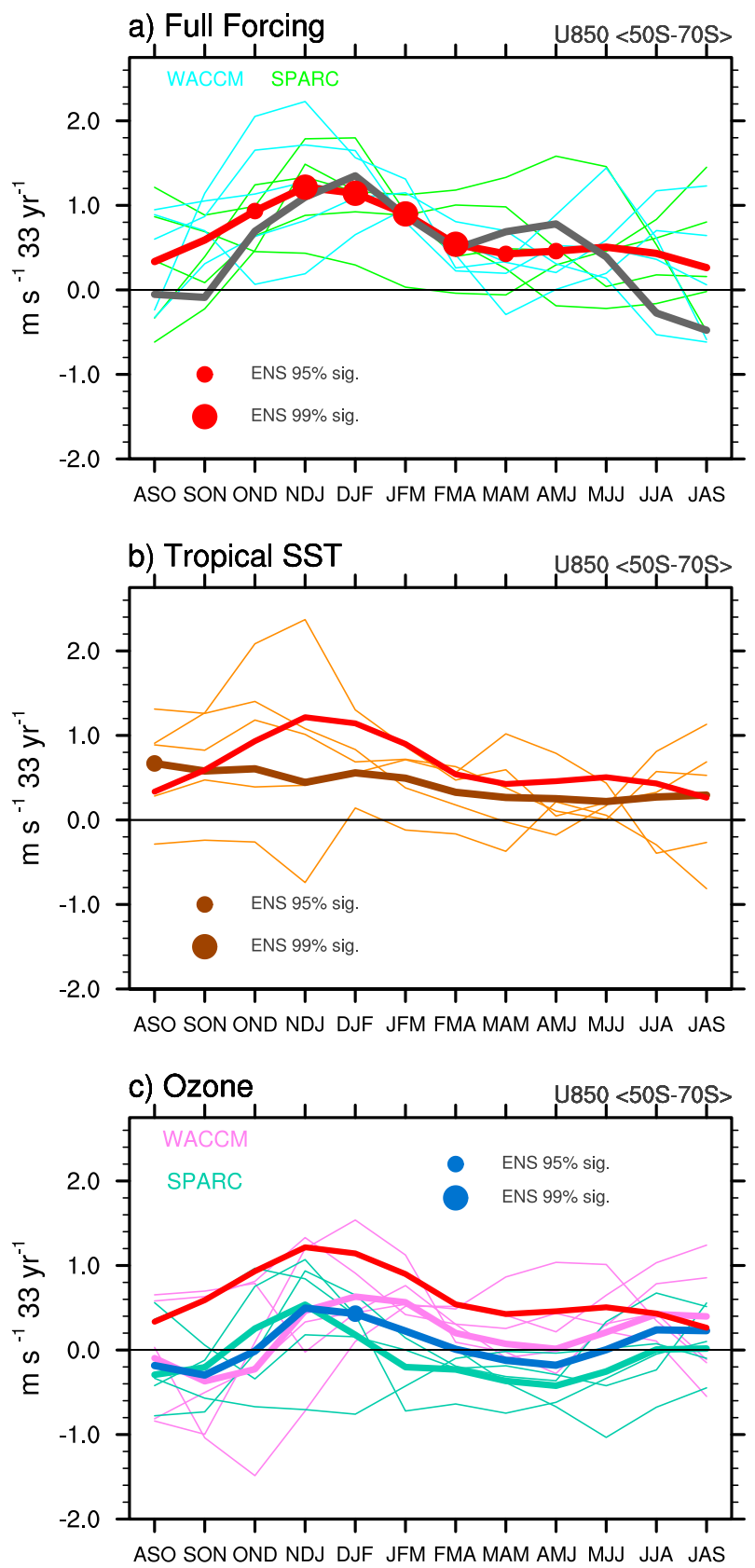

FIG. 6. Seasonal-mean trends in 850-hPa zonal wind for 19792011 , averaged over $50^{\circ}-70^{\circ} \mathrm{S}$, for the (a) Full Forcing, (b) TSST, and (c) Ozone ensembles. The thin lines correspond to individual ensemble members, and the thick lines represent the ensemblemean trends. The ensemble-mean trend associated with Full Forcing (red line) is repeated in (b) and (c). The gray line in (a) represents the reanalysis. The significance of the ensemblemean trends is indicated by markers.

all ensemble members. Comparing the stratospheric temperature trends of the Full Forcing ensemble mean with the responses to tropical SSTs (Fig. 10b) and ozone (Fig. 10c), it is clear that ozone largely explains the
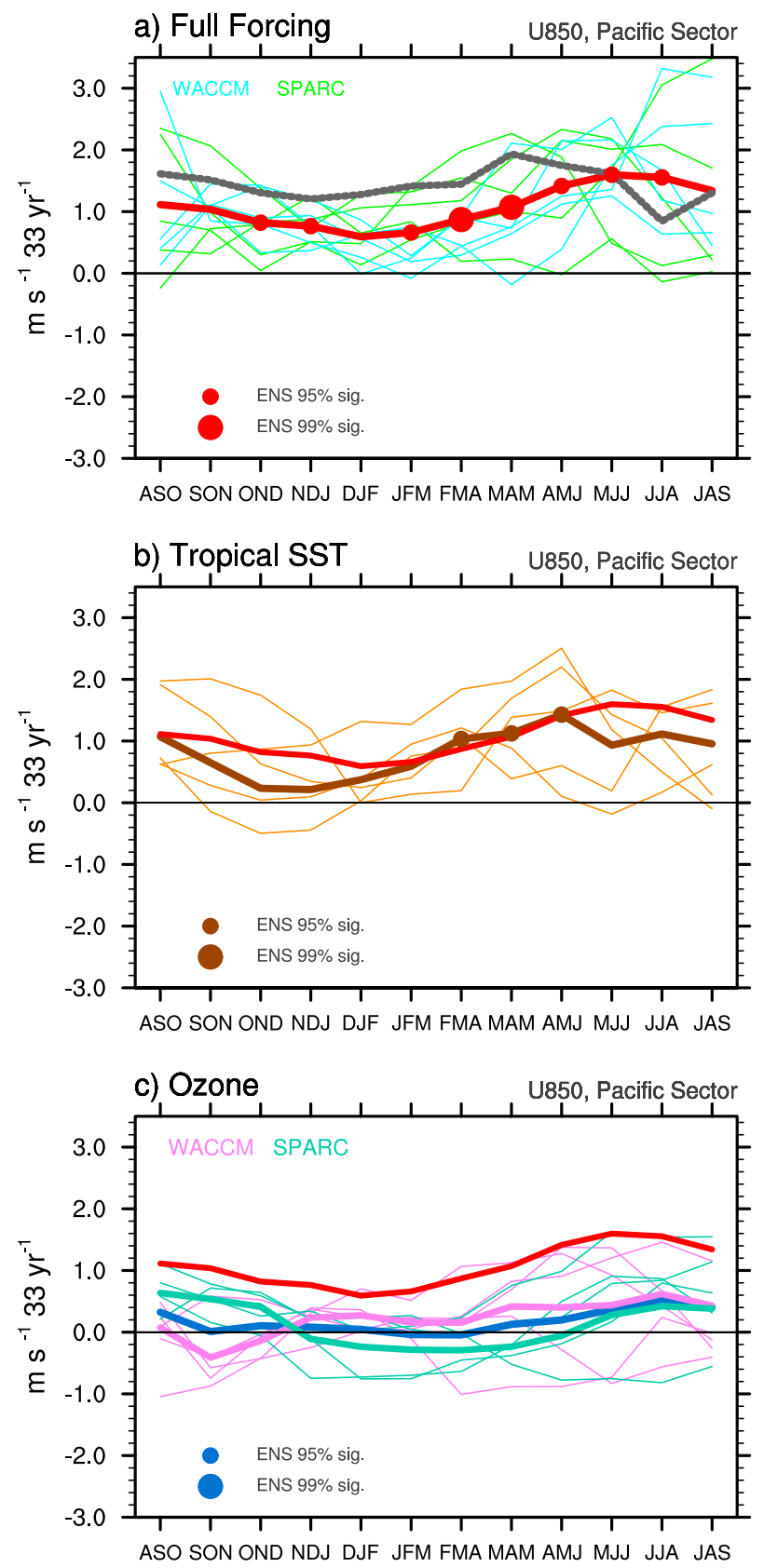

FIG. 7. As in Fig. 6, but for the Pacific sector $\left(40^{\circ}-60^{\circ} \mathrm{S}, 70^{\circ}-160^{\circ} \mathrm{W}\right)$ zonal winds.

cooling signal. The seasonality of peak cooling in late spring and early summer in the Full Forcing ensemble (Fig. 10a) mirrors that in the Ozone ensemble (Fig. 10c). Significant cooling in NDJ occurs in response to tropical SSTs (Fig. 10b), but considering individual members, cooling is not as consistent in the TSST ensemble as it is in the Ozone ensemble.

Figures 10a and 10c reveal differences between the responses to SPARC and WACCM ozone forcing. 

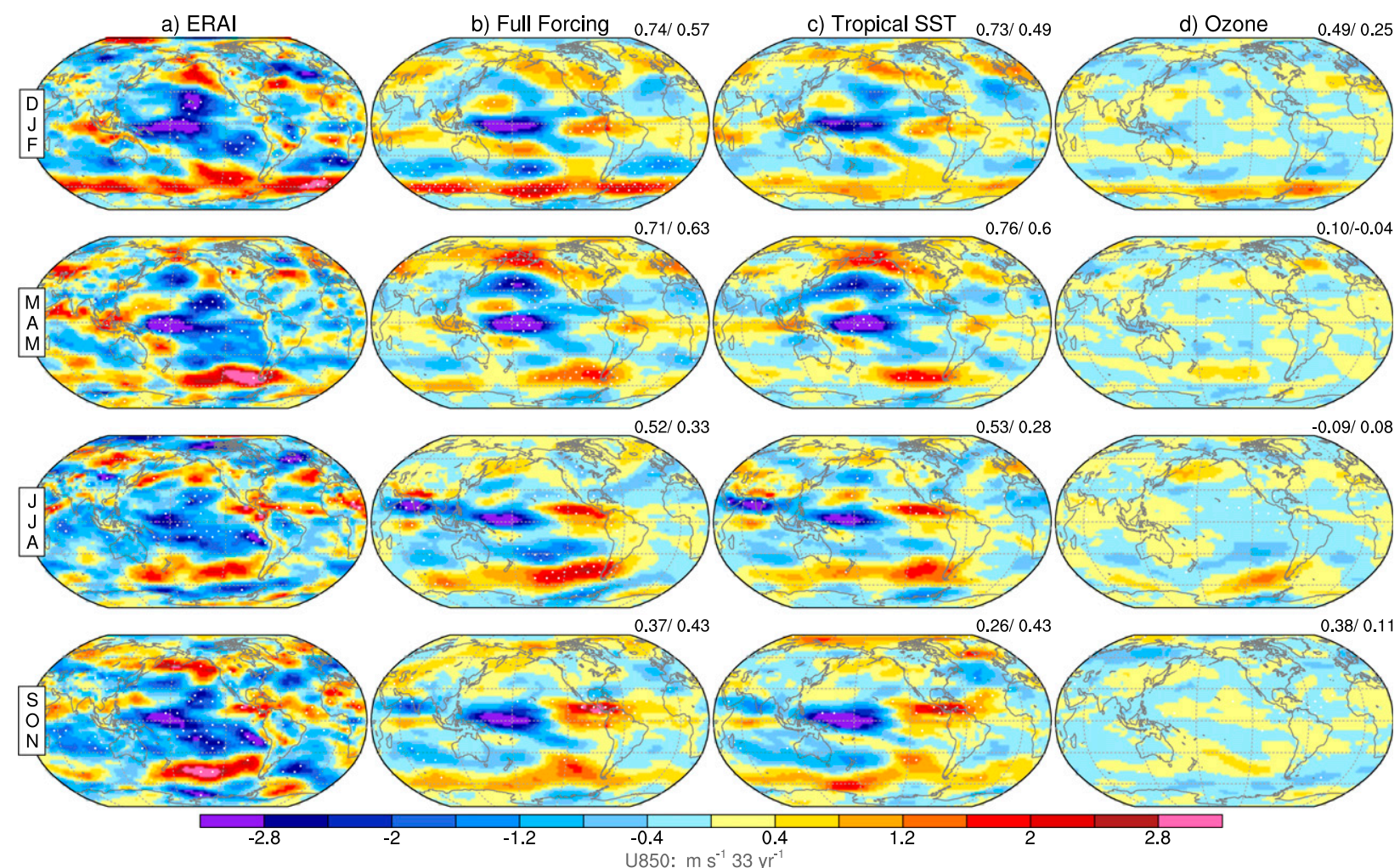

FIG. 8. Global maps of (top)-(bottom) seasonal-mean trends in 850-hPa zonal wind during 1979-2011, for (a) ERAI, (b) Full Forcing, (c) TSST, (d) Ozone. For all panels, white stippling indicates that the trend is significant at or above the 95\% level. The numbers at the top right of each map are the pattern correlations with the ERAI trend pattern over $30^{\circ}-70^{\circ} \mathrm{S}$ and globally.

These trend differences are most distinct in DJF and JFM, with WACCM showing more cooling than SPARC. During these seasons, each individual member of the WACCM ensemble cools more than any member of the SPARC ensemble. The persistence of strong cooling in the WACCM-forced runs through the summer likely arises from a bias in WACCM's polar vortex (e.g., Marsh et al. 2013). The seasonal timing of the cooling in ERAI, with peak values in OND and NDJ, is better replicated in the SPARC ensemble than in the WACCM ensemble. The SPARC ensemble mean actually has more cooling than does WACCM in SON and OND, although the individual ensemble members overlap. The differences in the responses to SPARC and WACCM ozone forcing can be seen more clearly in Fig. S3 of the supplemental material. The WACCM ensemble mean generally exhibits larger cooling, although the season of maximum cooling is delayed relative to SPARC.

Late spring stratospheric cooling associated with ozone loss has often been linked directly with a response of the midlatitude jet and near-surface westerlies in summer (e.g., Gillett and Thompson 2003; Polvani et al. 2011; Eyring et al. 2013). Ensemble-mean time series of polar stratospheric temperatures in spring (OND) and 850-hPa zonal winds in DJF from the Ozone and TSST experiments are shown in Fig. 11. In the Full Forcing ensemble mean, the OND polar stratospheric cooling trend is pronounced from the early 1980s through the early 1990s, after which the trend levels out (Fig. 11a). Ozone forcing (Fig. 11c) explains most of this trend. However, there is also a small but significant cooling trend in response to tropical SST variability (Fig. 11b), with a slightly different timing than that in response to ozone forcing. In particular, positive anomalies associated with tropical SST changes persist into the early 1990s, influencing the trend of the Full Forcing ensemble mean (Fig. 11a). Summer zonal wind anomalies from the Full Forcing ensemble mean (Fig. 11d) evolve nearly in step with the spring stratospheric temperature anomalies, increasing from the early 1980s through the early 1990 s, then leveling out. The spring stratospheric temperature and summer tropospheric wind time series are highly correlated $(r=-0.93)$, even after detrending $(r=-0.82)$.

Inspection of individual ensemble members reveals that lower-stratospheric cooling is not always associated with an intensification of the tropospheric westerly 

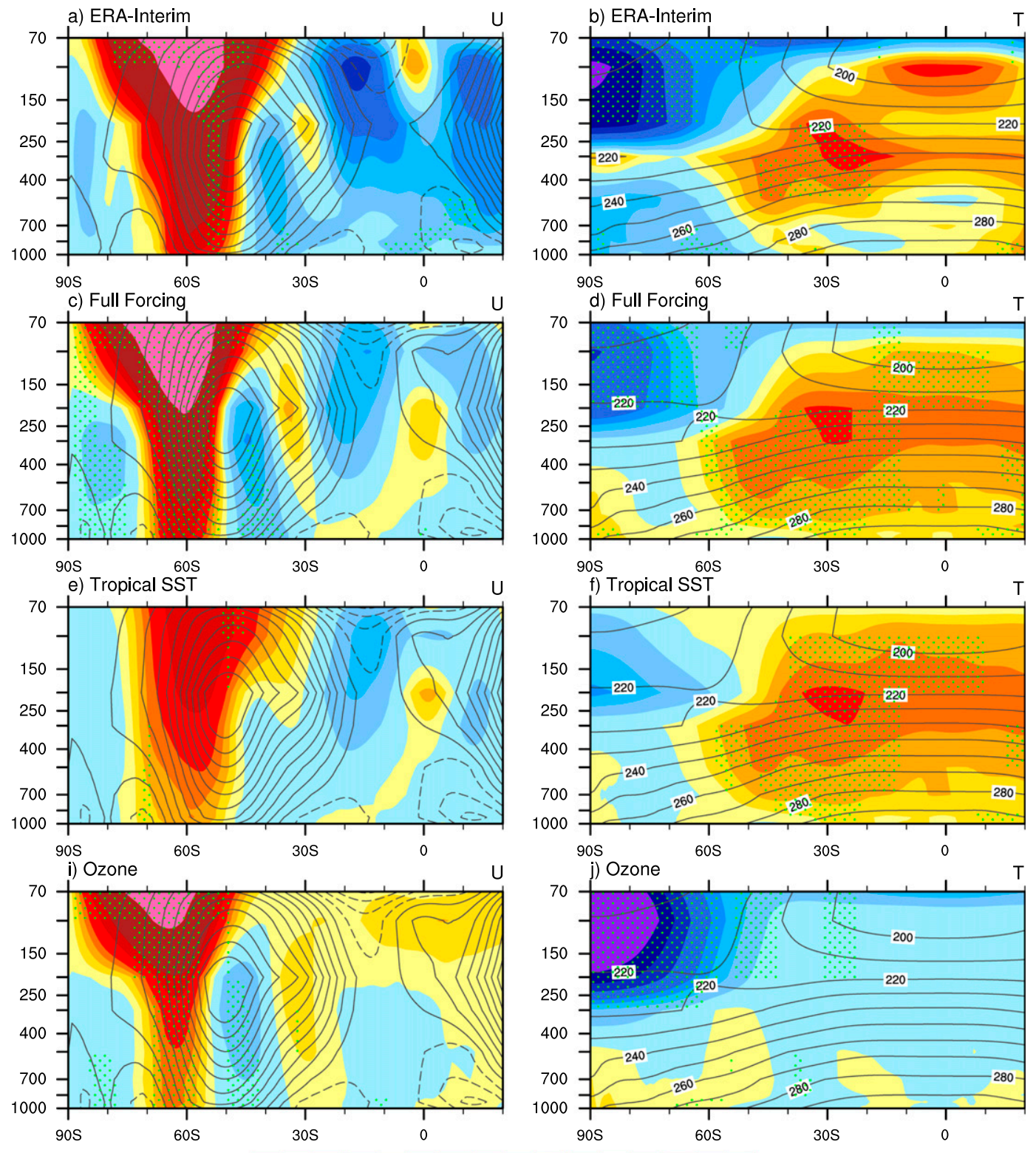

$\begin{array}{llllllllllllllll}-5 & -4 & -3 & -2 & -1.5 & -1 & -0.5 & 0 & 0.25 & 0.5 & 0.75 & 1 & 1.5 & 2 & 4\end{array}$

Wind: $\mathrm{m} \mathrm{s}^{-1} 33 \mathrm{yr}^{-1} \mid$ Temperature: ${ }^{\circ} \mathrm{C} 33 \mathrm{yr}^{-1}$

FIG. 9. Latitude-height plots of DJF (left) zonal-mean zonal wind and (right) temperature trends for 1979-2011: (a),(b) ERAI, and the ensemble-mean trends associated with (c),(d) Full Forcing, (e),(f) TSST, and (i),(j) Ozone ensembles. In all panels, color shading corresponds to the trend; black contours indicate the climatology, and green stippling indicates that the trend is significant at or above the $95 \%$ level. Note the nonlinear color scale. The zonal wind contour interval is $3.0 \mathrm{~m} \mathrm{~s}^{-1}$.

winds over $50^{\circ}-70^{\circ} \mathrm{S}$. Although all 10 Ozone ensemble members exhibit lower-stratospheric cooling in the late spring and early summer (Fig. 10c), the lowertropospheric wind trends are more variable (Fig. 6c). Figure 12 compares the summer zonal-mean temperature and zonal wind trends in the Ozone ensemble member with the weakest $850-\mathrm{hPa}$ wind trend and the
TSST ensemble member with the strongest $850-\mathrm{hPa}$ wind trend. The single TSST member exhibits a pattern of large zonal wind trends (Fig. 12c) poleward of $30^{\circ} \mathrm{S}$ that resembles the reanalysis (Fig. 9a) as well as the forced response to ozone depletion (Fig. 9g). In contrast, wind trends in the single Ozone ensemble member (Fig. 12e) are negative in the middle and lower 
a) Full Forcing

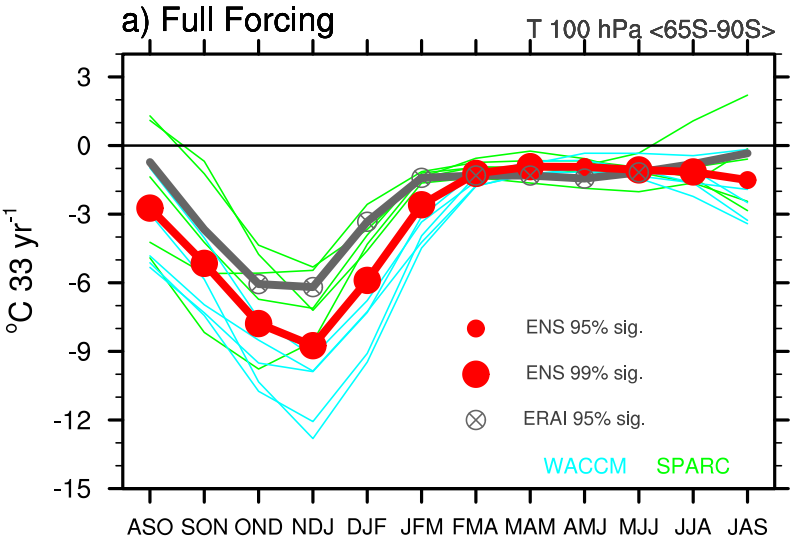

b) Tropical SST
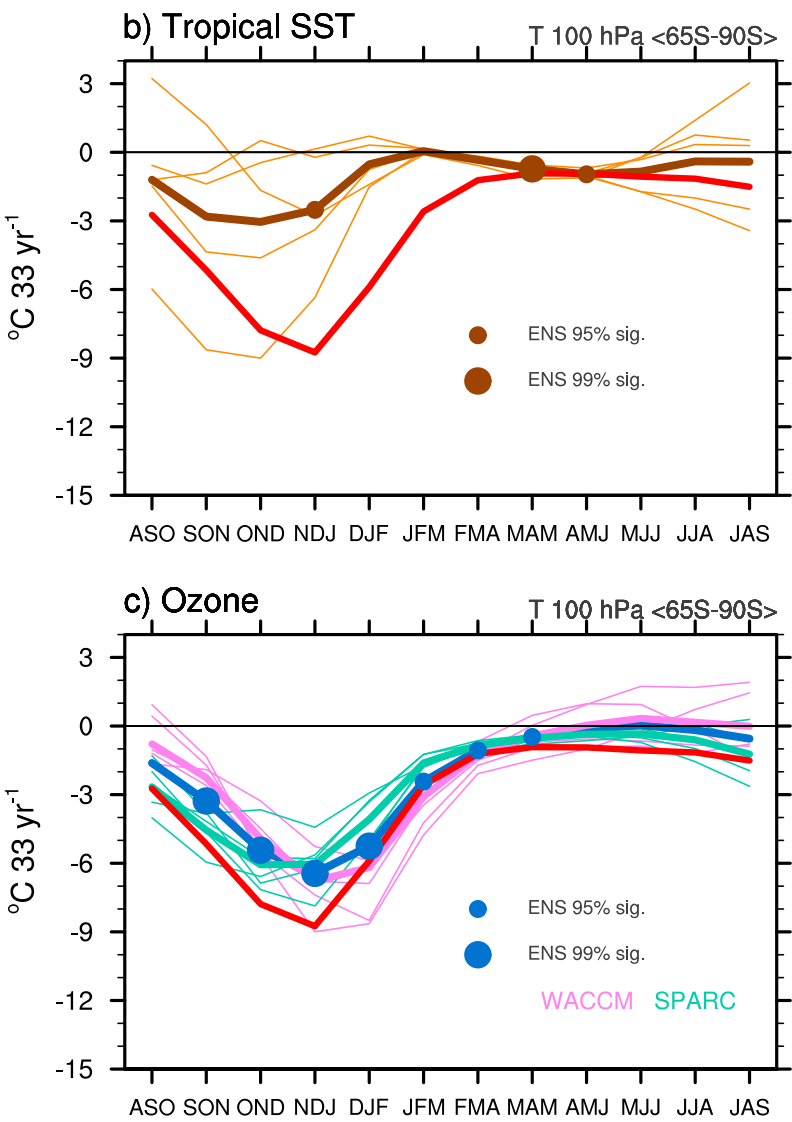

FIG. 10. As in Fig. 6, but for the lower polar stratospheric temperature $\left(100 \mathrm{hPa} ; 65^{\circ}-90^{\circ} \mathrm{S}\right)$.

troposphere over $50^{\circ}-70^{\circ} \mathrm{S}$, despite some significant polar stratospheric cooling (Fig. 12f). These results illustrate the role of intrinsic variability, which is important to recognize when relating the model results to the observed trends. While it can be said that the observed zonal wind trend is generally consistent with the forced response to ozone depletion, the wind field by itself does not provide a unique fingerprint of ozone depletion.

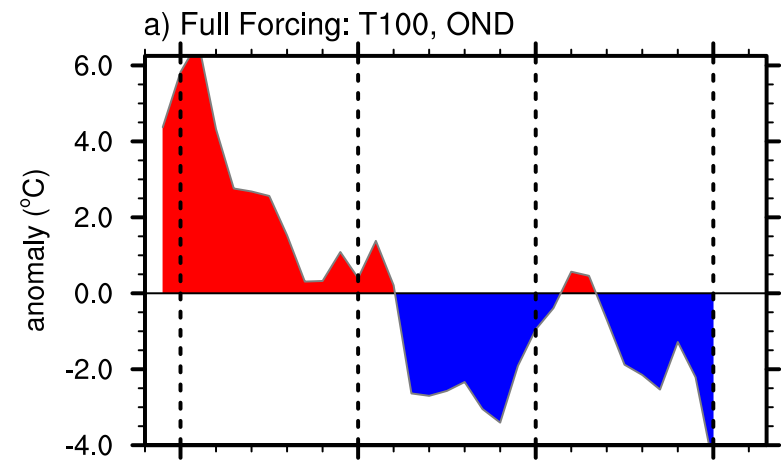

b) TSST: T100, OND

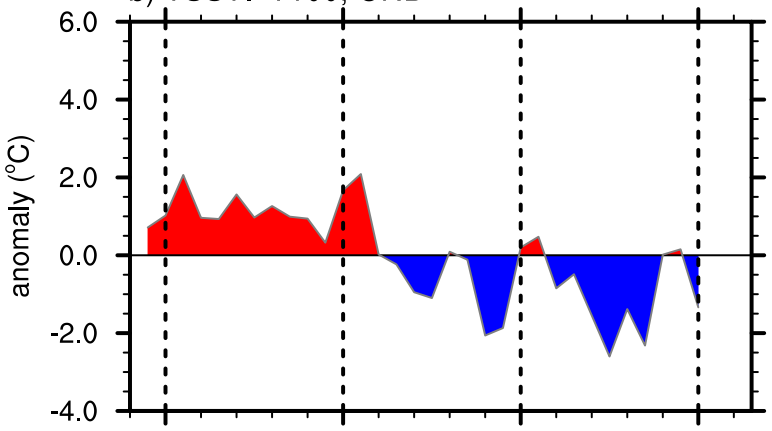

c) Ozone: T100, OND

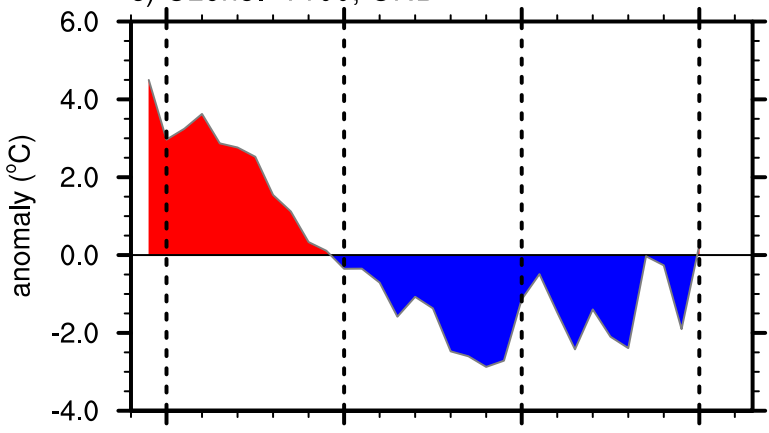

d) Full Forcing: U850, DJF

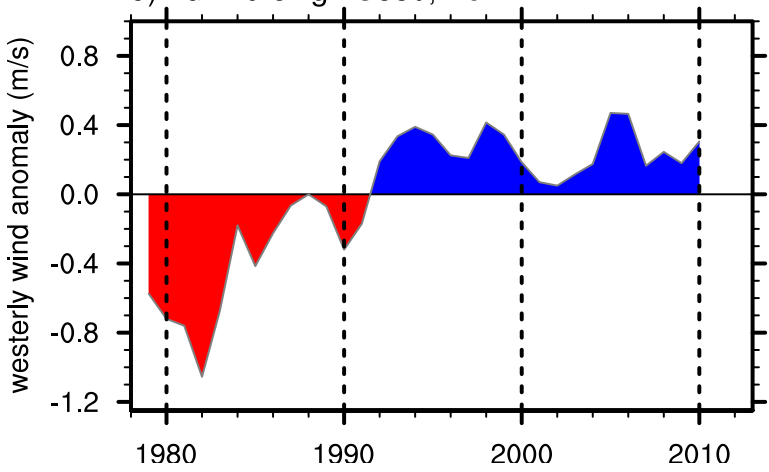

FIG. 11. Time series of ensemble-mean OND polar lower stratospheric temperature $\left(100 \mathrm{hPa} ; 65^{\circ}-90^{\circ} \mathrm{S}\right)$ associated with the (a) Full Forcing, (b) TSST, and (c) Ozone ensembles. (d) Ensemble-mean time series of DJF zonal winds averaged over $50^{\circ}-70^{\circ} \mathrm{S}$ associated with Full Forcing. 

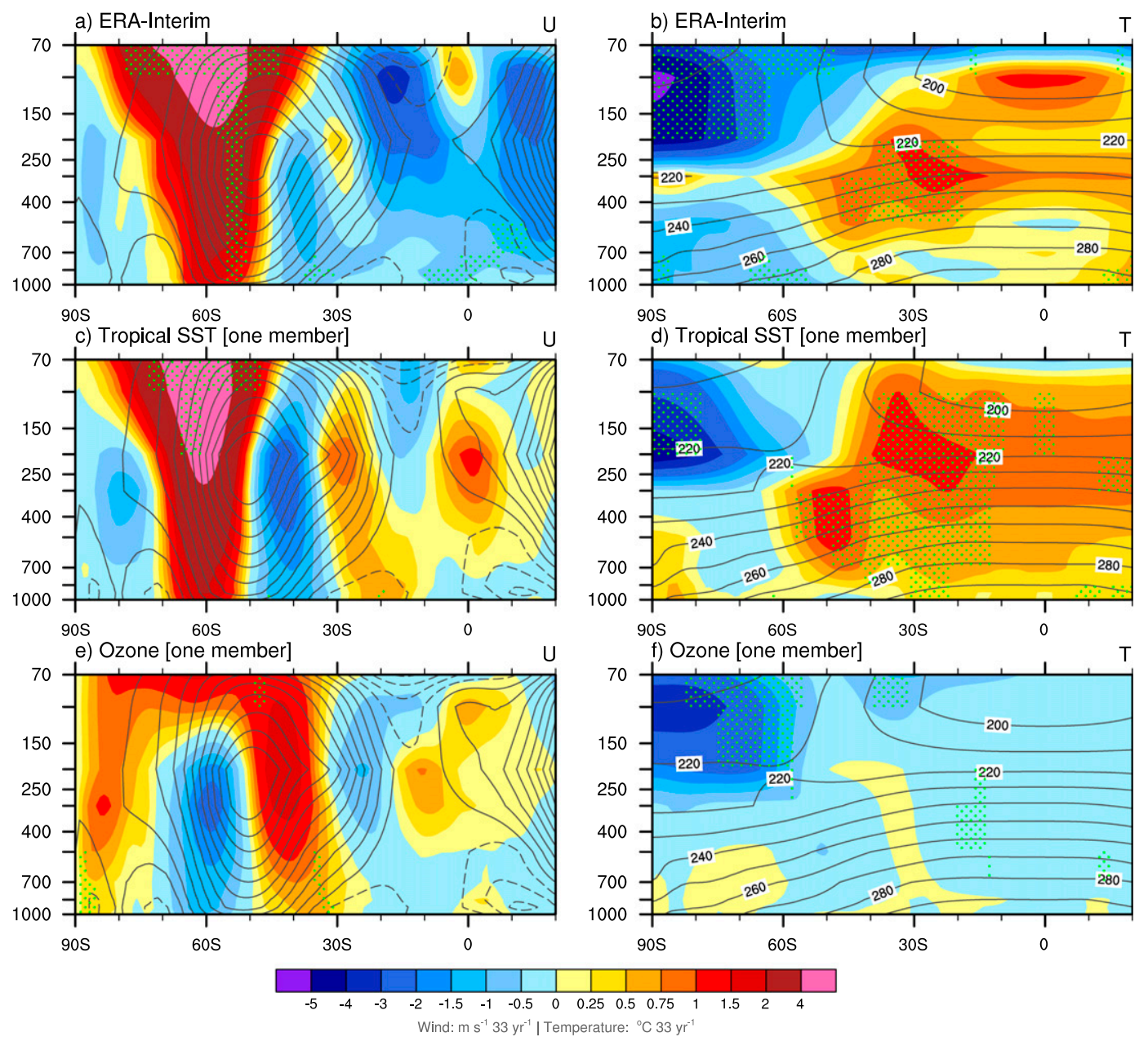

FIG. 12. As in Fig. 9, but showing trends associated with single ensemble members of the TSST and Ozone ensembles instead of the ensemble-mean trends.

\section{d. Pacific sector zonal wind variability and its causes}

Returning to the Pacific sector, tropical variability dominates the variability of the winds in both reanalysis and the model runs. As discussed earlier, there is a significant correlation of $r=0.55$ between the tropical winds (Fig. 13a) and the Pacific sector winds (Fig. 13b). In the model simulations, the time series of the Pacific sector winds from the Full Forcing ensemble mean (Fig. 13c) is correlated at $r=0.83$ (with 2-month smoothing) with the reanalysis tropical wind time series. The correlation is nearly as high if only the TSST ensemble mean is used (Fig. 13d, $r=0.81$ ). The decadal-scale variability in these indices is consistent with the PDO (Fig. 13e). Interannual ENSO variability, as measured by the Niño-3.4 index (Fig. 13f), is also reflected in these time series, but the ENSO index lacks the shift in the late 1990s that is captured by the PDO index (Fig. 13e) and the central equatorial Pacific zonal winds (Fig. 13a).
The robust atmospheric circulation response to the prescribed tropical SSTs can be understood by analogy to a La Niña state, in which stronger-than-normal trade winds are associated with enhanced zonal gradients in SSTs and SLP. The cooling imposed in the central and eastern tropical Pacific leads to higher SLP by reducing the flux of heat to the atmosphere, decreasing buoyancy, and vice versa for the warming imposed in the western tropical Pacific and other ocean basins. The low-level winds respond to the enhanced pressure gradients, leading to a region of low-level divergence over the central Pacific (Fig. 8b). As seen in Fig. 14, this divergence is associated with reduced convective rainfall, which in turns provides the anomalous latent heating that drives the Rossby wave response.

One aspect of the results that we have not yet examined is the seasonality of the tropical forcing and why the most significant SH wind response to tropical SSTs occurs in autumn (MAM). Figure 14 shows seasonal maps 
a) ERAI: Equatorial Pacific U850

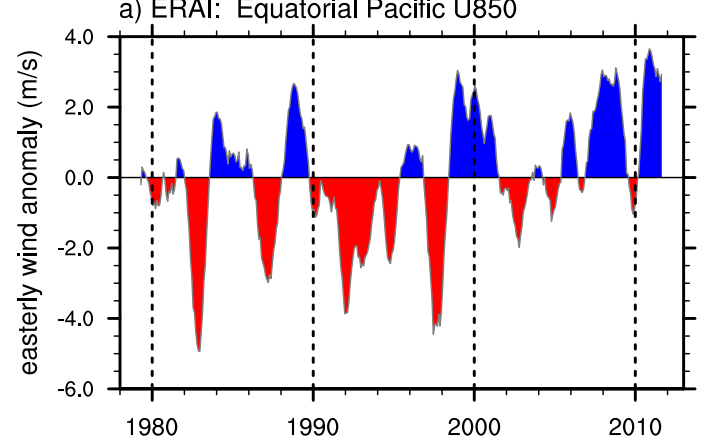

c) Full Forcing: Pacific Sector U850

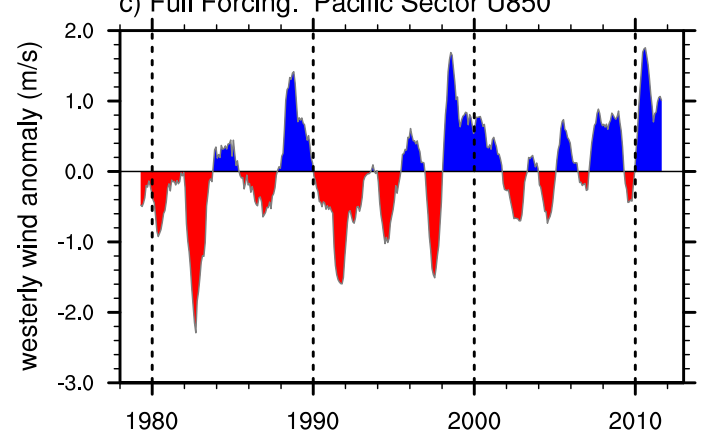

e) observed PDO index (inverted)

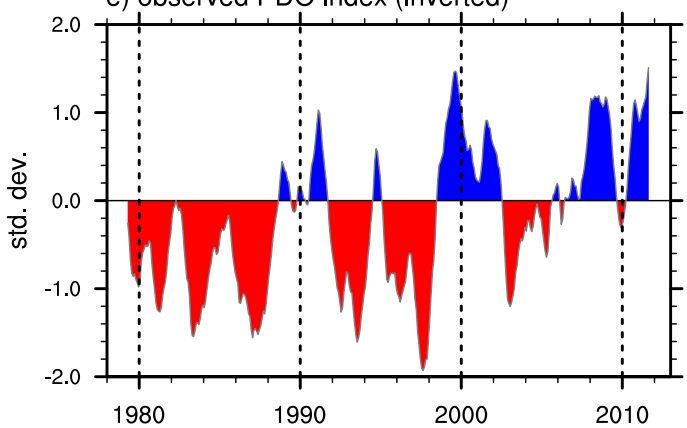

b) ERAI: Pacific Sector U850

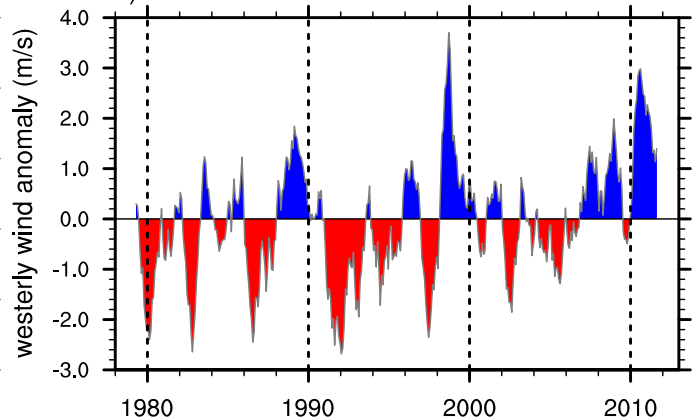

d) Tropical SST: Pacific Sector U850

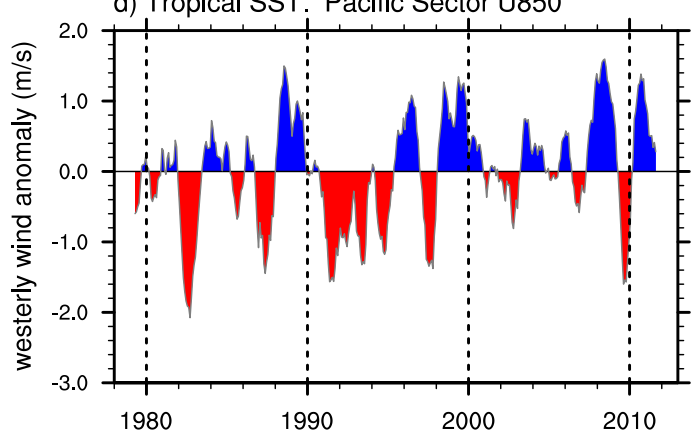

f) observed NINO 3.4 index (inverted)

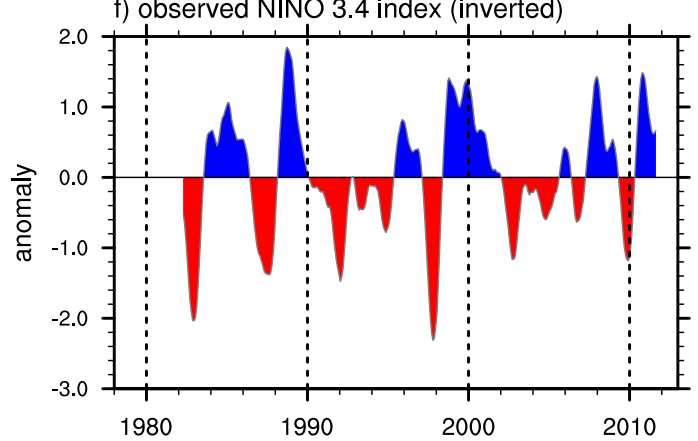

FIG. 13. (a) Time series of ERAI 850-hPa zonal wind anomalies from the equatorial Pacific repeated from Fig. 3d. The 850-hPa zonal wind anomalies from the Pacific sector of the Southern Ocean for (b) ERAI, and the ensemblemeans associated with (c) Full Forcing and (d) TSST. (e) The monthly PDO index based on the first EOF of detrended North Pacific SST anomalies (see Trenberth et al. 2014 for definition); (f) the Niño-3.4 index from the NOAA/Climate Prediction Center. For clarity, each time series is smoothed by a 2-month running mean.

of the prescribed SST trends together with diagnostics of the responses in tropical convection and upper-level atmospheric circulation. Consistent with the seasonality of the Pacific sector wind response to tropical SST forcing, the tropical convective and Rossby wave responses are also seasonal. In MAM (Fig. 14c), the 200-hPa streamfunction field bears clear signatures of poleward-propagating Rossby waves from the tropics into both hemispheres. In the SH high latitudes, the 200-hPa streamfunction anomalies are focused on the Pacific sector in MAM, in contrast to other seasons, when they are more diffuse and zonally symmetric, consistent with the lower-tropospheric wind anomalies in Fig. 8c. The waves originate from the cyclonic streamfunction anomalies straddling the equator over the cool SSTs between $120^{\circ} \mathrm{W}$ and the date line. As indicated by the velocity potential trends (Fig. 14d), upper-level convergence is focused on this region, consistent with the reduced rainfall. Enhanced rainfall and upper-level divergence occur across the western Pacific, completing an east-west dipole pattern that resembles the Southern Oscillation.

The convective responses are different in JJA and SON than in MAM, even though the underlying SST trend patterns are similar. In JJA and SON, the largest negative convective rainfall trends and the largest 

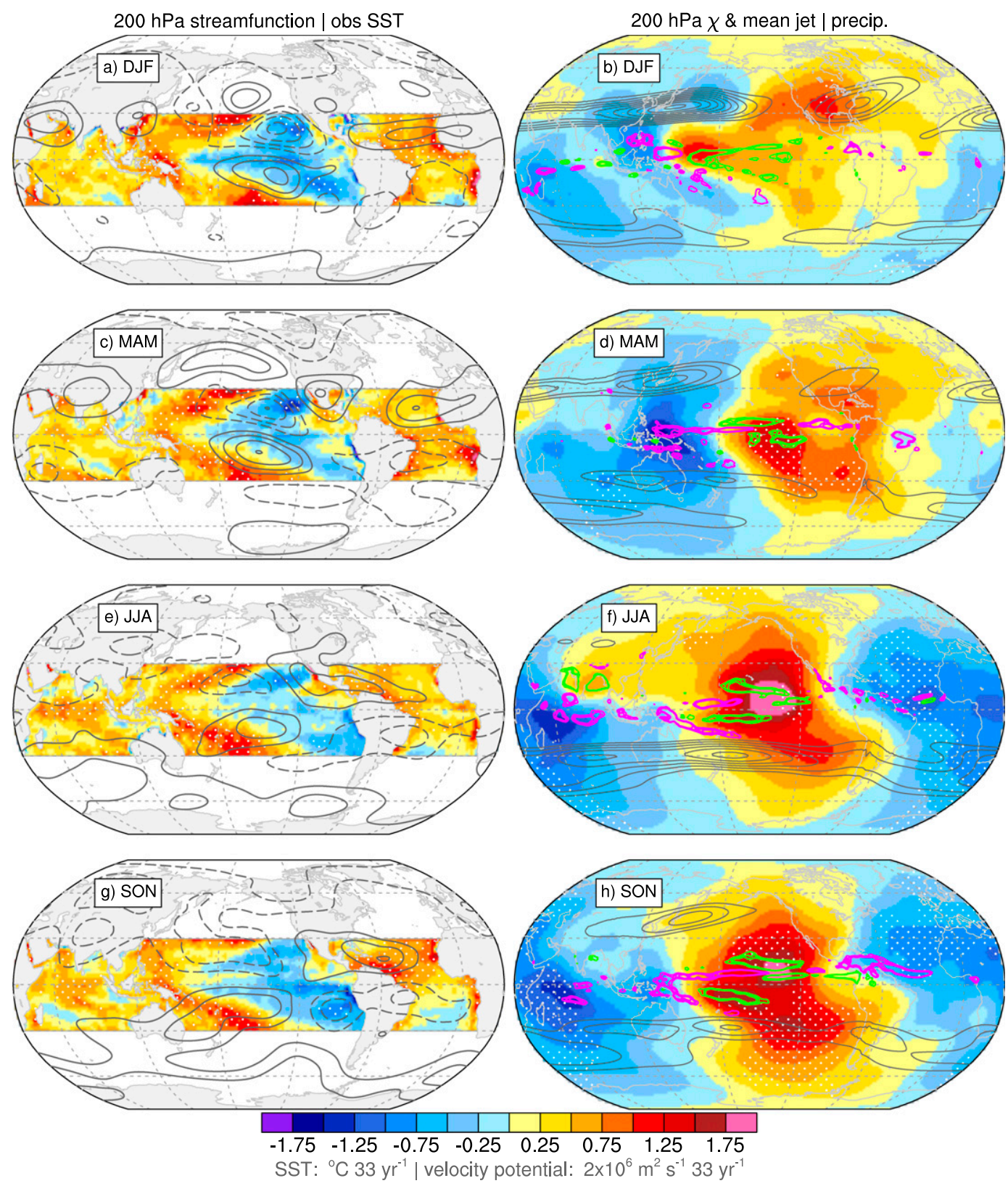

FIG. 14. Maps showing diagnostics of the seasonal-mean convective and Rossby wave responses to tropical SST forcing during 1979-2011. (left) Prescribed SST trends (color scale) and simulated 200-hPa streamfunction trends (gray contours); negative contours (dashed) and positive contours (solid), with an interval of $\pm 2 \times 10^{6} \mathrm{~m}^{2} \mathrm{~s}^{-1}$ $(33 \mathrm{yr})^{-1}$. (right) The 200-hPa velocity potential $\chi$ trends (color bar), convective rainfall trends (colored contours), and 200-hPa zonal wind climatology (gray contours), all from the model. Positive $\chi$ trends indicate convergence, and negative trends indicate divergence. Negative rainfall trends are in green contours and positive rainfall trends are in magenta contours, with intervals of $\pm 1.25, \pm 1.5$, and $\pm 1.75 \mathrm{~mm} \mathrm{day}^{-1}(33 \mathrm{yr})^{-1}$. Zonal wind is contoured at $5 \mathrm{~m} \mathrm{~s}^{-1}$, starting at $30 \mathrm{~m} \mathrm{~s}^{-1}$.

upper-level convergence trends occur north of the equator (Figs. 14f,h), minimizing their influence on the SH circulation: the cyclonic center of action immediately south of the equator in the streamfunction field is half the magnitude it is in MAM. The seasonality of the convective responses could be a function of the mean state and the migration of the ITCZ into the summer hemisphere. Additionally, Rossby wave propagation depends on the location of convection with respect to the position and strength of the subtropical jets (e.g., Seo 
and Son 2012; Bao and Hartmann 2014; Li et al. 2015), which are also shown in Fig. 14. There is a split jet in MAM (Fig. 14d) and strong subtropical jets in JJA and SON (Figs. 14f,h). Recent observational analyses (Adames and Wallace 2014) and model studies (Bao and Hartmann 2014) suggest that Rossby waves extract energy from the exit regions of split jets but can be trapped in the tropics by strong subtropical jets.

In DJF, both the convective responses in the tropics (Fig. 14b) and the Rossby wave propagation in the SH (Fig. 14c) are rather weak. The weak subtropical jet in DJF (Fig. 14b) likely plays a role in the lack of wave propagation (e.g., Jin and Kirtman 2009; Ding et al. 2012). Instead, the summer response to tropical SST anomalies projects onto the SAM, consistent with observational studies (e.g., L'Heureux and Thompson 2006; Ciasto et al. 2015). We conclude that the seasonality of the Pacific sector wind response to tropical SSTs largely reflects the seasonality of the convective responses in the tropical Pacific, as well as the seasonality of Rossby wave propagation.

\section{Discussion}

We have highlighted the seasonal and regional asymmetries in the westerly wind trends over the Southern Ocean during 1979-2011 and discussed these in the context of the forced responses to tropical SSTs and stratospheric ozone depletion as given by CAM4. Although both low-frequency tropical variability and ozone depletion have been linked with Antarctic climate change, ours is one of the first studies to directly compare and quantify their relative importance. In light of the simultaneous trends in tropical SSTs and in polar stratospheric ozone depletion, 1979-2011 is a particularly interesting time period for our analysis. The tropical SST trends include the signature of the negative phase of the PDO, marked by cooling in the eastern Pacific. Warming trends across the rest of the tropical oceans include the impacts of rising GHGs.

We find that both tropical SSTs and ozone depletion contribute to the intensification of the westerly winds over the Southern Ocean, with the largest trends in the Pacific sector. In our experiments, nonozone radiative forcings (including GHGs) do not have a significant role in directly forcing the winds. Seasonally, the most significant trends in both the reanalysis and the simulated zonally symmetric, SAM-like pattern occur in NDJ and DJF. Depending on the ozone dataset, the ozonerelated contribution to the westerly wind trend in DJF ranges from about 0.18 to $0.62 \mathrm{~m} \mathrm{~s}^{-1}(33 \mathrm{yr})^{-1}$, compared with the tropical SST contribution of about $0.56 \mathrm{~m} \mathrm{~s}^{-1}$ $(33 \mathrm{yr})^{-1}$ (Fig. 6). In the Pacific sector, both the model and observations show significant trends in the autumn, and the model experiments suggest that the autumn trend is largely driven by tropical SSTs.

Our results extend recent work suggesting an influence of the tropics on the summer SAM. A number of studies have shown significant interannual correlations between eastern Pacific tropical SSTs and the SAM index in observations (e.g., L'Heureux and Thompson 2006; Ding et al. 2012; Schneider et al. 2012b; Ciasto et al. 2015). Ding et al. (2014a) go a step further by removing the signal of ENSO variability from the observations and suggest that the SAM trend is driven in part by tropical warming, thereby providing observational support for the modeling work of Lu et al. (2008) and Sun et al. (2013). In a follow-up modeling study, Ding et al. (2014b) show a tropical influence on the summer SAM trend by relaxing the atmospheric state to observations in the tropics. Our results broadly confirm this influence using a different model and methodology. However, our analysis does not break down the zonally symmetric response to tropical SST anomalies in terms of an ENSO-like and a global warming response (e.g., $\mathrm{Lu}$ et al. 2008). This will be the subject of future work.

This study joins a number of studies that have linked recent atmospheric circulation trends over the Southern Ocean and Antarctica to tropical variability (e.g., Ding et al. 2011; Ding and Steig 2013; Li et al. 2014; 2015; Simpkins et al. 2014; Schneider et al. 2012a). The general physical arguments explaining these linkages are broadly consistent across the studies. For example, Ding and Steig (2013) link a cyclonic circulation trend over the Bellingshausen Sea with rapid warming on the Antarctic Peninsula during 1979-2009, showing that both the circulation and warming trends are strongest in MAM (Ding and Steig 2013). Consistent with our work explaining the strengthening zonal winds in the Pacific sector, Ding and Steig (2013) attribute this circulation trend to tropical Pacific forcing, using an atmospheric model coupled to a slab ocean in the extratropics. Similar to our TSST experiments, Ding and Steig (2013) prescribe observed SSTs in the tropics. Both studies attribute autumn circulation trends in the Pacific sector to a poleward-propagating Rossby wave originating over the equatorial Pacific between about $120^{\circ} \mathrm{W}$ and $180^{\circ}$.

Earlier work by a similar team of authors (Ding et al. 2011) suggested that central tropical Pacific warming during austral winter has driven an atmospheric Rossby wave response, leading to anomalous high pressure in the Amundsen-Bellingshausen Sea region. This agrees with our work in illustrating that the high-latitude $\mathrm{SH}$ circulation is sensitive to anomalous forcing in the central tropical Pacific. However, the scenario of central 
Pacific warming and a strong wintertime anticyclonic circulation trend in the high-latitude SH does not fit the reanalysis or SST trends during 1979-2011. The SH circulation trends in JJA are characterized by a small, negative SAM trend with stronger centers of action over the continent than over the ocean (their Fig. 1 and our Fig. 4). The negative SAM trend is within the ensemble spread of our experiments (Fig. 6a). In contrast, Ding et al.'s (2011) central Pacific warming experiment produces a localized wave train pattern in the South Pacific that does not resemble the SAM (their Fig. 4). The discrepancy in the sign of the central tropical Pacific SST change can be reconciled by the different time periods and methods used. Ding et al. (2011) apply a superposed epoch analysis to the SSTs, differencing the periods 1979-93 and 1994-2009. The latter period mixes the two phases of the PDO (Fig. 13e), and the epoch difference shows a small warming in the central tropical Pacific. If the latter epoch instead starts in 1999, then the PDO pattern, with cooling in the central and eastern Pacific and warming in the western Pacific, is evident in the epoch difference map (see Fig. 3 in Trenberth et al. 2014). Ding et al.'s (2011) experiment is highly idealized in that a monopole of warming is prescribed over the central tropical Pacific, the magnitude of which is scaled to one of the leading patterns of SST covariability with SH geopotential height, not to the actual SST trend. In contrast, our TSST experiment is based on the observed SST field, and the anomalous negative heating over the central tropical Pacific arises from the zonal SST gradient. This leads to an extratropical atmospheric circulation response that resembles the trends in the reanalysis (Fig. 5).

In our Tropical SST experiment, the Rossby wave response is weaker in winter and spring than in autumn, resulting in an insignificant wind response in the $\mathrm{SH}$. This seems inconsistent with the findings of $\mathrm{Li}$ et al. (2014) and Simpkins et al. (2014), who connected tropical Atlantic SST trends with SH winter and spring circulation trends, respectively. Our experiments show some support for a role of the Atlantic in JJA and SON evident in the increased convective rainfall and upperlevel divergence during these seasons over the Atlantic (Figs. 14f,h). However, the Atlantic trends are much smaller than the convective anomalies over the Pacific, suggesting that the Pacific plays the stronger role. Also, unlike Li et al. (2014), who suggest that tropical PacificAntarctic connections are limited to interannual ENSO time scales, we find significant decadal variability in the tropical Pacific is clearly linked with circulation anomalies over the Southern Ocean in both the observations and our model experiments (Fig. 13). While our results do not rule out a role for the tropical Atlantic in the $\mathrm{SH}$ circulation trends, care must be taken to carefully compare the results of idealized experiments to observations. In general, if one region is forced in an AGCM experiment, the rest of the global atmosphere will respond, and the response patterns will tend to project onto the preferred modes of variability, such as the second mode of zonal wind variability (Fig. 2d), which is related to fluctuations in the Amundsen Sea low. The Li et al. (2014) and Simpkins et al. (2014) experiments are more similar to Ding et al. (2011) than to the TSST experiment described here, in that only one region of the tropical ocean surface is forced. Finally, while these previous studies have associated Rossby wave forcing with anomalous heating over the tropical oceans, anomalous cooling is equally effective at driving wavelike responses (e.g., Trenberth et al. 2014).

Our results highlighting the role of tropical SST variability in SH zonal wind trends since 1979 might seem to contradict previous work suggesting that ozone depletion has been the main driver of $\mathrm{SH}$ atmospheric circulation trends (e.g., Polvani et al. 2011; Previdi and Polvani 2014; Thompson et al. 2011). We hypothesized that the coincidence of ozone loss with the PDO trend is important for understanding the zonal wind trends over the Southern Ocean during 1979-2011. The studies emphasizing ozone's dominant role in the wind trends analyzed somewhat different time periods. According to the forcing datasets, the downward trend in ozone concentration largely occurred between the late 1960s and mid-1990s, with a large fraction of the total ozone loss occurring before the 1979 start date of our analysis (Fig. 1.). In contrast, the PDO was positive throughout much of the 1980s and 1990s before shifting to its negative phase in 1998 (Fig. 13e). Thus, the period of strongest ozone loss occurred prior to the most recent major shift in tropical climate.

As a point of discussion, we briefly investigate whether ozone has a larger relative influence on the circulation over the primary period of ozone loss, the period 1960-2000 (consistent with Polvani et al. 2011). During this period, there is very little trend in the PDO, as its two phases (negative in the 1960s-70s, positive in the 1980s-90s) largely cancel (see Fig. 2 in Trenberth et al. 2014). For the SAM-like pattern (Fig. 15), the Full Forcing ensemble-mean trend has seasonality similar to the 1979-2011 period, with the largest trends in the late spring and summer and smallest trends in winter (Fig. 15a). Comparing this trend to the ensemble-mean trends in the TSST (Fig. 15b) and Ozone ensembles (Fig. 15c), it is apparent that ozone dominates the overall trend in the Full Forcing ensemble. The TSST ensemble mean has no significant trend in any season, while the Ozone ensemble mean has positive and 

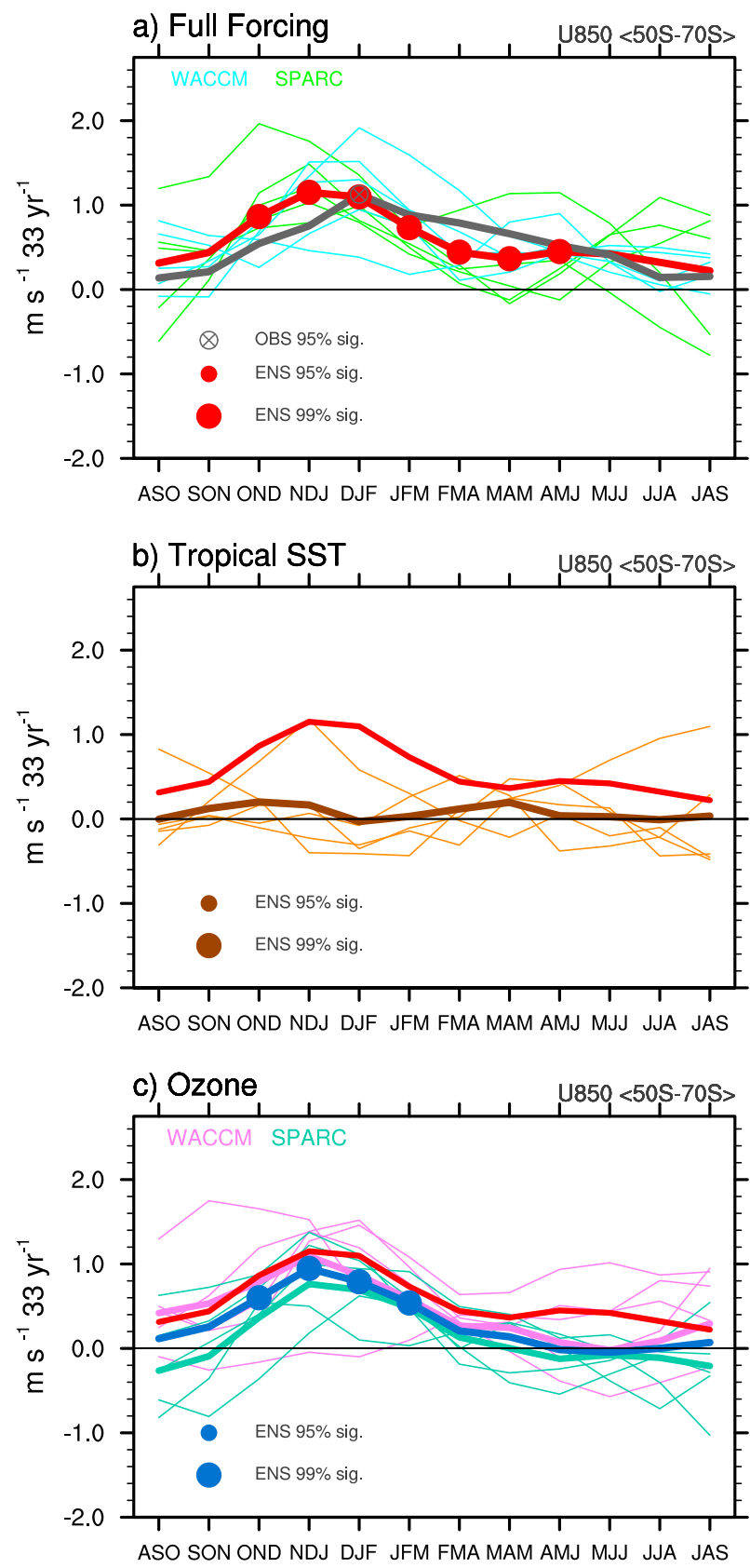

FIG. 15. As in Fig. 6, but 1960-2000 is used instead of 1979-2011. The observed zonal wind trends are inferred from the trend of the Marshall (2003) SAM index: the detrended monthly SAM index was regressed on the detrended index of $850-\mathrm{hPa}$ zonal wind from ERAI (Fig. 3e), and the regression coefficient was multiplied by the 1960-2000 seasonal-mean trends in the SAM index.

significant trends from the late spring through late summer. The SNRs in DJF for the Full Forcing and Ozone ensembles are 2.5 and 1.6, respectively. In the Pacific sector, the ensemble-mean trends are largely insignificant during 1960-2000 (not shown). Thus, we conclude that our results are consistent with previous studies that emphasized the dominant role of ozone depletion in the $\mathrm{SH}$ atmospheric circulation trends during 1960-2000. Further, our work extends this previous research to illustrate that the relative roles of tropical SSTs and ozone depletion are dependent on the time period considered.

The choice of the SPARC or WACCM ozone dataset does not change the key results in either the 1979-2011 or the 1960-2000 period. For 1979-2011, ozone forcing alone is insufficient to explain the DJF SAM-like trend in the Full Forcing ensemble mean. WACCM ozone produces a larger ensemble-mean wind response than does SPARC ozone, but there is considerable overlap among the ensemble members (Fig. 6c), even though the stratospheric cooling trends are more distinguishable (Fig. 10c). Large intrinsic variability in the tropospheric wind field blurs the distinctions between the responses to the two ozone datasets. For the longer 1960-2000 period, when the intrinsic variability is somewhat more muted and the ensemble-mean ozone-induced trends are more statistically significant, the zonal wind responses to SPARC and WACCM ozone forcing are even more similar (Fig. 15c and Fig. S2 in the supplemental material). For the $850-\mathrm{hPa} 50^{\circ}-70^{\circ} \mathrm{S}$ DJF zonal wind index, the 1960-2000 trend associated with SPARC is $0.24 \mathrm{~m} \mathrm{~s}^{-1}(10 \mathrm{yr})^{-1}$, while the trend associated with WACCM is approximately $9 \%$ larger, $0.26 \mathrm{~m} \mathrm{~s}^{-1}(10 \mathrm{yr})^{-1}$. Of the 10 Ozone ensemble members, only one exhibits a negative trend, and this one belongs to the WACCM ensemble (Fig. 15c).

The importance of the relative phasing of tropical decadal variability with ozone depletion has implications for the interpretation of free-running, coupled models, whose externally forced (e.g., ensemble mean) circulation trends over the Southern Ocean do not capture the zonal asymmetry of recent changes (Haumann et al. 2014) nor the strength of the zonal wind trend in summer (Mahlstein et al. 2013). While these models could be missing or misrepresenting key physics, one process they likely lack is the observed evolution of tropical climate, which we find could explain both of these deficiencies in their circulation trends over the Southern Ocean. In turn, the wind field is important for many other aspects of Southern Ocean climate dynamics. For instance, sea ice-ocean models suggest that recent trends in the Southern Ocean sea ice cover are a response to the wind forcing (Zhang 2014; Holland et al. 2014).

The time period dependence of the relative roles of tropical SSTs and ozone, and the difficulties in distinguishing the responses to the two ozone datasets, in part reflects the role of intrinsic, unforced atmospheric variability in shaping circulation trends on regional 
scales. In interpreting the observed SAM trend, it is important to recall that the SAM is the leading mode of variability in the $\mathrm{SH}$ atmospheric circulation and can exhibit trends over various time scales that arise simply from internal dynamics. Therefore, caution should be exercised when associating observed trends in recent decades with the forced response to ozone (e.g., Kang et al. 2011), as the observed trends may also be explained by a combination of intrinsic variability and a forced response to tropical SST trends. Clearly identifying the signature of ozone depletion in $\mathrm{SH}$ climate requires a long time period or an evaluation of multiple variables, such as the lower polar stratospheric temperature. According to our results, the most robust evidence for a significant role of ozone depletion in the tropospheric circulation trend lies in the combination of: (i) the seasonality of the trend in the SAM-like pattern (e.g., Fig. 6); (ii) the seasonal signature of ozone in the lower polar stratospheric temperature (e.g., Fig. 10); and (iii) the correlation of the zonal wind time series with the lower polar stratospheric temperature (e.g., Fig. 11).

As the interaction of ozone depletion and tropically generated variability with intrinsic, unforced atmospheric variability has played a key role in shaping Antarctic and Southern Ocean climate change over the past 30 years, it is almost certain that similar interactions will play a key role in climate change over the next 30 years. Such interactions may involve a different combination of external forcings than was important for the recent past. For example, stratospheric ozone levels are expected to recover, while GHGs are likely to rapidly increase. Understanding the interactions of these trends with internal variability should continue to be a topic of ongoing study.

Acknowledgments. The authors thank three anonymous reviewers for constructive reviews that led to a much improved paper. We thank Adam Phillips for conducting the Tropical SST ensemble, for assistance with configuring and postprocessing the other simulations, and for computing the monthly PDO index. Lorenzo Polvani engaged in valuable discussions that led to the direct comparison of SPARC- and WACCM-driven simulations. James Screen kindly provided Antarctic upper-air temperature data based on Screen and Simmonds (2012). The Niño-3.4 index was obtained from the NOAA/Climate Prediction Center (http:// www.cpc.ncep.noaa.gov/data/indices/sstoi.indices). David Schneider was supported by National Science Foundation (NSF) Grants 1048899 and 1235231. Tinting Fan was supported by the China Scholarship Council. The figures were produced with the NCAR Command Language software package. The simulations discussed here can be accessed through the Climate Variability and Change Working Group of the Community Earth System Model (http://www.cesm.ucar.edu/working_groups/ Climate/experiments/cesm1.0/).

\section{REFERENCES}

Adames, Á. F., and J. M. Wallace, 2014: Three-dimensional structure and evolution of the MJO and its relation to the mean flow. J. Atmos. Sci., 71, 2007-2026, doi:10.1175/ JAS-D-13-0254.1.

Adler, R. F., and Coauthors, 2003: The Version-2 Global Precipitation Climatology Project (GPCP) monthly precipitation analysis (1979-present). J. Hydrometeor., 4, 1147-1167, doi:10.1175/1525-7541(2003)004<1147:TVGPCP > 2.0.CO;2.

Bao, M., and D. L. Hartmann, 2014: The response to MJO-like forcing in a nonlinear shallow-water model. Geophys. Res. Lett., 41, 1322-1328, doi:10.1002/2013GL057683.

Bracegirdle, T. J., 2013: Climatology and recent increase of westerly winds over the Amundsen Sea derived from six reanalyses. Int. J. Climatol., 33, 843-851, doi:10.1002/joc.3473.

— pospheric pressure and temperature in the latest global reanalyses. J. Climate, 25, 7138-7146, doi:10.1175/ JCLI-D-11-00685.1.

Ciasto, L. M., G. R. Simpkins, and M. H. England, 2015: Teleconnections between tropical Pacific SST anomalies and extratropical Southern Hemisphere climate. J. Climate, 28, 56-65, doi:10.1175/JCLI-D-14-00438.1.

Cionni, I., and Coauthors, 2011: Ozone database in support of CMIP5 simulations: Results and corresponding radiative forcing. Atmos. Chem. Phys., 11, 11267-11292, doi:10.5194/ acp-11-11267-2011.

Dee, D. P., and Coauthors, 2011: The ERA-Interim reanalysis: Configuration and performance of the data assimilation system. Quart. J. Roy. Meteor. Soc., 137, 553-597, doi:10.1002/ qj. 828 .

Deser, C., and A. S. Phillips, 2009: Atmospheric circulation trends, 1950-2000: The relative roles of sea surface temperature forcing and direct atmospheric radiative forcing. J. Climate, 22, 396-413, doi:10.1175/2008JCLI2453.1.

,,-- M. A. Alexander, and B. V. Smoliak, 2014: Projecting North American climate over the next 50 years: Uncertainty due to internal variability. J. Climate, 27, 2271-2296, doi:10.1175/JCLI-D-13-00451.1.

Ding, H., R. J. Greatbatch, and G. Gollan, 2014a: Tropical impact on the interannual variability and long-term trend of the Southern Annular Mode during austral summer from 1960/ 1961 to 2001/2002. Climate Dyn., 44, 2215-2228, doi:10.1007/ s00382-014-2299-x.

,-- , and,$- 2014 \mathrm{~b}$ : Tropical influence independent of ENSO on the austral summer Southern Annular Mode. Geophys. Res. Lett., 41, 3643-3648, doi:10.1002/2014GL059987.

Ding, Q., and E. J. Steig, 2013: Temperature change on the Antarctic Peninsula linked to the tropical Pacific. J. Climate, 26, 7570-7585, doi:10.1175/JCLI-D-12-00729.1.

,$- \ldots$, D. S. Battisti, and M. Küttel, 2011: Winter warming in West Antarctica caused by central tropical Pacific warming. Nat. Geosci., 4, 398-403, doi:10.1038/ngeo1129.

,,--- , and J. M. Wallace, 2012: Influence of the tropics on the southern annular mode. J. Climate, 25, 6330-6348, doi:10.1175/JCLI-D-11-00523.1. 
England, M. H., and Coauthors, 2014: Recent intensification of winddriven circulation in the Pacific and the ongoing warming hiatus. Nat. Climate Change, 4, 222-227, doi:10.1038/nclimate2106.

Eyring, V., and Coauthors, 2013: Long-term ozone changes and associated climate impacts in CMIP5 simulations. J. Geophys. Res., 118, 5029-5060, doi:10.1002/jgrd.50316.

Gent, P. R., and Coauthors, 2011: The Community Climate System Model version 4. J. Climate, 24, 4973-4991, doi:10.1175/ 2011JCLI4083.1.

Gillett, N. P., and D. W. J. Thompson, 2003: Simulation of recent Southern Hemisphere climate change. Science, 302, 273-275, doi:10.1126/science.1087440.

Grise, K. M., and L. M. Polvani, 2014: The response of midlatitude jets to increased $\mathrm{CO}_{2}$ : Distinguishing the roles of sea surface temperature and direct radiative forcing. Geophys. Res. Lett., 41, 6863-6871, doi:10.1002/2014GL061638.

Hassler, B., P. J. Young, R. W. Portmann, G. E. Bodeker, J. S. Daniel, K. H. Rosenlof, and S. Solomon, 2013: Comparison of three vertically resolved ozone data sets: Climatology, trends and radiative forcings. Atmos. Chem. Phys., 13, 5533-5550, doi:10.5194/acp-13-5533-2013.

Haumann, F. A., D. Notz, and H. Schmidt, 2014: Anthropogenic influence on recent circulation-driven Antarctic sea ice changes. Geophys. Res. Lett., 41, 8429-8437, doi:10.1002/2014GL061659.

Holland, P. R., and R. Kwok, 2012: Wind-driven trends in Antarctic sea-ice drift. Nat. Geosci., 5, 872-875, doi:10.1038/ngeo1627.

- N. Bruneau, C. Enright, M. Losch, N. T. Kurtz, and R. Kwok, 2014: Modeled trends in Antarctic sea ice thickness. J. Climate, 27, 3784-3801, doi:10.1175/JCLI-D-13-00301.1.

Hurrell, J. W., J. J. Hack, D. Shea, J. M. Caron, and J. Rosinski, 2008: A new sea surface temperature and sea ice boundary dataset for the Community Atmosphere Model. J. Climate, 21, 5145-5153, doi:10.1175/2008JCLI2292.1.

Jin, D., and B. P. Kirtman, 2009: Why the Southern Hemisphere ENSO responses lead ENSO. J. Geophys. Res., 114, D23101, doi:10.1029/2009JD012657.

Kang, S. M., L. M. Polvani, J. C. Fyfe, and M. Sigmond, 2011: Impact of polar ozone depletion on subtropical precipitation. Science, 332, 951-954, doi:10.1126/science.1202131.

Kay, J. E., and Coauthors, 2015: The Community Earth System Model (CESM) Large Ensemble project: A community resource for studying climate change in the presence of internal climate variability. Bull. Amer. Meteor. Soc., 96, 1333-1349, doi:10.1175/BAMS-D-13-00255.1.

Kushner, P. J., I. M. Held, and T. L. Delworth, 2001: Southern Hemisphere atmospheric circulation response to global warming. J. Climate, 14, 2238-2249, doi:10.1175/ 1520-0442(2001)014<0001:SHACRT $>2.0$. CO 2 .

Le Quéré, C., and Coauthors, 2007: Saturation of the Southern Ocean $\mathrm{CO}_{2}$ sink due to recent climate change. Science, $\mathbf{3 1 6}$, 1735-1738, doi:10.1126/science.1136188.

L'Heureux, M. L., and D. W. J. Thompson, 2006: Observed relationships between the El Niño-Southern Oscillation and the extratropical zonal-mean circulation. J. Climate, 19, 276-287, doi:10.1175/JCLI3617.1.

Li, X., D. M. Holland, E. P. Gerber, and C. Yoo, 2014: Impacts of the north and tropical Atlantic Ocean on the Antarctic Peninsula and sea ice. Nature, 505, 538-542, doi:10.1038/nature12945.

— E. P. Gerber, D. M. Holland, and C. Yoo, 2015: A Rossby wave bridge from the tropical Atlantic to West Antarctica. J. Climate, 28, 2256-2273, doi:10.1175/JCLI-D-14-00450.1.

Lovenduski, N. S., N. Gruber, and S. C. Doney, 2008: Toward a mechanistic understanding of the decadal trends in the
Southern Ocean carbon sink. Global Biogeochem. Cycles, 22, GB3016, doi:10.1029/2007GB003139.

Lu, J., G. Chen, and D. M. W. Frierson, 2008: Response of the zonal mean atmospheric circulation to El Niño versus global warming. J. Climate, 21, 5835-5851, doi:10.1175/2008JCLI2200.1.

Mahlstein, I., P. R. Gent, and S. Solomon, 2013: Historical Antarctic mean sea ice area, sea ice trends, and winds in CMIP5 simulations. J. Geophys. Res., 118, 5105-5110, doi:10.1002/ jgrd.50443.

Marsh, D. R., M. J. Mills, D. E. Kinnison, J.-F. Lamarque, N. Calvo, and L. M. Polvani, 2013: Climate change from 1850 to 2005 simulated in CESM1(WACCM). J. Climate, 26, 73727391, doi:10.1175/JCLI-D-12-00558.1.

Marshall, G. J., 2003: Trends in the southern annular mode from observations and reanalyses. J. Climate, 16, 4134-4143, doi:10.1175/1520-0442(2003)016<4134:TITSAM>2.0.CO;2.

_ 2007: Half-century seasonal relationships between the Southern Annular mode and Antarctic temperatures. Int. J. Climatol., 27, 373-383, doi:10.1002/joc.1407.

Neale, R. B., J. Richter, S. Park, P. H. Lauritzen, S. J. Vavrus, P. J. Rasch, and M. Zhang, 2013: The mean climate of the Community Atmosphere Model (CAM4) in forced SST and fully coupled experiments. J. Climate, 26, 5150-5168, doi:10.1175/ JCLI-D-12-00236.1.

Neely, R. R., D. R. Marsh, K. L. Smith, S. M. Davis, and L. M. Polvani, 2014: Biases in Southern Hemisphere climate trends induced by coarsely specifying the temporal resolution of stratospheric ozone. Geophys. Res. Lett., 41, 8602-8610, doi:10.1002/2014GL061627.

Nicolas, J. P., and D. H. Bromwich, 2014: New reconstruction of Antarctic near-surface temperatures: Multidecadal trends and reliability of global reanalyses. J. Climate, 27, 8070-8093, doi:10.1175/JCLI-D-13-00733.1.

Polvani, L. M., D. W. Waugh, G. J. P. Correa, and S.-W. Son, 2011: Stratospheric ozone depletion: The main driver of twentiethcentury atmospheric circulation changes in the Southern Hemisphere. J. Climate, 24, 795-812, doi:10.1175/2010JCLI3772.1.

Previdi, M., and L. M. Polvani, 2014: Climate system response to stratospheric ozone depletion and recovery. Quart. J. Roy. Meteor. Soc., 140, 2401-2419, doi:10.1002/qj.2330.

Raphael, M., and Coauthors, 2015: The Amundsen Sea low: Variability, change, and impact on Antarctic climate. Bull. Amer. Meteor. Soc., 97, doi:10.1175/BAMS-D-14-00018.1, in press.

Sallée, J. B., K. G. Speer, and S. R. Rintoul, 2010: Zonally asymmetric response of the Southern Ocean mixed-layer depth to the southern annular mode. Nat. Geosci., 3, 273-279, doi:10.1038/ngeo812.

Santer, B. D., T. M. L. Wigley, J. S. Boyle, D. J. Gaffen, J. J. Hnilo, D. Nychka, D. E. Parker, and K. E. Taylor, 2000: Statistical significance of trends and trend differences in layer-average atmospheric temperature time series. J. Geophys. Res., 105, 7337-7356, doi:10.1029/1999JD901105.

Schneider, D. P., C. Deser, and Y. Okumura, 2012a: An assessment and interpretation of the observed warming of West Antarctica in the austral spring. Climate Dyn., 38, 323-347, doi:10.1007/s00382-010-0985-x.

_, Y. Okumura, and C. Deser, 2012b: Observed Antarctic interannual climate variability and tropical linkages. J. Climate, 25, 4048-4066, doi:10.1175/JCLI-D-11-00273.1.

Screen, J. A., and I. Simmonds, 2012: Half-century air temperature change above Antarctica: Observed trends and spatial reconstructions. J. Geophys. Res., 117, D16108, doi:10.1029/ 2012JD017885. 
Seo, K.-H., and S.-W. Son, 2012: The global atmospheric circulation response to tropical diabatic heating associated with the Madden-Julian oscillation during northern winter. J. Atmos. Sci., 69, 79-96, doi:10.1175/2011JAS3686.1.

Simpkins, G. R., S. McGregor, A. S. Taschetto, L. M. Ciasto, and M. H. England, 2014: Tropical connections to climatic change in the extratropical Southern Hemisphere: The role of Atlantic SST trends. J. Climate, 27, 4923-4936, doi:10.1175/ JCLI-D-13-00615.1.

Son, S.-W., and Coauthors, 2010: Impact of stratospheric ozone on Southern Hemisphere circulation change: A multimodel assessment. J. Geophys. Res., 115, D00M07, doi:10.1029/ 2010JD014271.

Staten, P. W., J. J. Rutz, T. Reichler, and J. Lu, 2012: Breaking down the tropospheric circulation response by forcing. Climate Dyn., 39, 2361-2375, doi:10.1007/s00382-011-1267-y.

Sun, L., G. Chen, and J. Lu, 2013: Sensitivities and mechanisms of the zonal mean atmospheric circulation response to tropical warming. J. Atmos. Sci., 70, 2487-2504, doi:10.1175/ JAS-D-12-0298.1.

Thompson, D. W. J., and J. M. Wallace, 2000: Annular modes in the extratropical circulation. Part I: Month-to-month variability. J. Climate, 13, 1000-1016, doi:10.1175/1520-0442(2000) 013<1000:AMITEC > 2.0.CO;2.

- , and S. Solomon, 2002: Interpretation of recent Southern Hemisphere climate change. Science, 296, 895-899, doi:10.1126/science.1069270.

- — - P. J. Kushner, M. H. England, K. M. Grise, and D. J. Karoly, 2011: Signatures of the Antarctic ozone hole in
Southern Hemisphere surface climate change. Nat. Geosci., 4, 741-749, doi:10.1038/ngeo1296.

Trenberth, K. E., J. T. Fasullo, G. Branstator, and A. S. Phillips, 2014: Seasonal aspects of the recent pause in surface warming. Nat. Climate Change, 4, 911-916, doi:10.1038/nclimate2341.

Vallis, G. K., P. Zurita-Gotor, C. Cairns, and J. Kidston, 2014: Response of the large-scale structure of the atmosphere to global warming. Quart. J. Roy. Meteor. Soc., 141, 1479-1501, doi:10.1002/qj.2456.

van Vuuren, D. P., and Coauthors, 2011: The representative concentration pathways: An overview. Climatic Change, 109, 531, doi:10.1007/s10584-011-0148-z.

Waugh, D. W., L. Oman, P. A. Newman, R. S. Stolarski, S. Pawson, J. E. Nielsen, and J. Perlwitz, 2009: Effect of zonal asymmetries in stratospheric ozone on simulated Southern Hemisphere climate trends. Geophys. Res. Lett., 36, L18701, doi:10.1029/2009GL040419.

Wilson, A. B., D. H. Bromwich, K. M. Hines, and S. Wang, 2014: El Niño flavors and their simulated impacts on atmospheric circulation in the high southern latitudes. J. Climate, 27, 89348955, doi:10.1175/JCLI-D-14-00296.1.

Young, P. J., S. M. Davis, B. Hassler, S. Solomon, and K. H. Rosenlof, 2014: Modeling the climate impact of Southern Hemisphere ozone depletion: The importance of the ozone data set. Geophys. Res. Lett., 41, 9033-9039, doi:10.1002/ 2014GL061738.

Zhang, J., 2014: Modeling the impact of wind intensification on Antarctic sea ice volume. J. Climate, 27, 202-214, doi:10.1175/ JCLI-D-12-00139.1. 